\title{
THE QUANTITATIVE DETERMINATION OF IRON KINETICS AND HEMOGLOBIN SYNTHESIS IN HUMAN SUBJECTS *
}

\author{
By MYRON POLLYCOVE ANd ROBERT MORTIMER \\ (From the Donner Laboratory, Donner Pavilion, and the Lawrence Radiation Laboratory, \\ University of California, Berkeley; and the Radioisotope Service and Medical \\ Service, Veterans Administration Hospital, Boston, Mass.)
}

(Submitted for publication July 25, 1960 ; accepted January 26, 1961)

Two-thirds of the iron normally present in the body is in hemoglobin. Hemoglobin turnover is generally accepted to be much greater than turnover of iron in storage depots, in which nearly all of the remaining iron is found. For these reasons it was anticipated that hemoglobin synthesis might be measured directly by means of radioactive iron. The pioneering work of Huff and Elmlinger and their associates (1-3) proposed that hemoglobin synthesis could be determined from the product of the rate of removal of iron from plasma (plasma iron turnover, milligrams per day) and the fraction of radioactive iron incorporated into circulating erythrocytes. Further studies by Huff and others (4-16), however, revealed that hemoglobin synthesis calculated in this way was consistently greater than would be expected from relating circulating hemoglobin to well established data concerning the life span of erythrocytes. Plasma iron turnover data yielded daily hemoglobin synthesis rates of 1.2 to 2.0 per cent of circulating hemoglobin as contrasted with expected rates of 0.75 to 1.00 per cent corresponding to an erythrocyte life span range of 100 to 130 days (17-20).

Although plasma iron turnover can be used for relative comparisons of erythropoiesis under certain circumstances, it is apparent that plasma iron turnover must be analyzed into its component parts before it can be used for quantitative determination of hemoglobin synthesis. This study was undertaken in an attempt to quantitate hemoglobin synthesis. For this purpose, mathematical models were developed that are compatible with experimental data obtained from over 400 subjects. Sequential measurements of radioiron were made in plasma, red cells, and at the body surface $(21,22)$. Data obtained from 13 normal subjects and 6 patients with endogenous hemochromatosis are pre-

* This investigation was supported in part by a grant from the United States Public Health Service (C-1440). sented in this report and analyzed in accordance with the proposed models. Most patients with endogenous hemochromatosis are not anemic and show normal blood and marrow erythrons upon histologic examination, suggesting normal hemoglobin synthesis and erythrocyte life span (23). Iron kinetics in these patients is greatly altered by a marked pathologic increase of iron stores. Study of patients with endogenous hemochromatosis therefore provides an especially useful test of the proposed iron kinetics model.

\section{MATERIALS AND METHODS}

All normal subjects ( 1 female and 12 male volunteers between the ages of 24 and 72 years) studied with the methods presented are included in this report. All were asymptomatic, in good health, with normal hematologic values.

All patients with endogenous hemochromatosis studied ( 6 males) are included in this report. None had received blood transfusion or iron therapy. Five of these patients were between 50 and 60 years old, with characteristic slate-grey or leaden, dusky skin color, and diabetes. Diagnosis was established by the abnormally increased concentration of iron in plasma (178 to $278 \mu \mathrm{g}$ per $100 \mathrm{ml}$ ), decreased total plasma iron-binding capacity (224 to $278 \mu \mathrm{g}$ per $100 \mathrm{ml}$ ), and liver biopsy demonstrating characteristic periportal fibrosis in association with massive deposits of hemosiderin. The sixth patient was only 22 years old; although biopsy of his liver demonstrated markedly increased amounts of hemosiderin, no periportal fibrosis was present. Glucose tolerance and cardiac and hepatic function were normal. Plasma iron concentration (149 $\mu \mathrm{g}$ per $100 \mathrm{ml}$ ) and total binding capacity $(314 \mu \mathrm{g}$ per $100 \mathrm{ml})$ were normal; he had not been venesected. The diagnosis was established by demonstration of increased absorption of ingested iron [29 per cent of $4 \mathrm{mg}$ iron (ferrous citrate) without ascorbic acid], in association with a striking familial incidence of endogenous hemochromatosis-his father and one paternal uncle had died with endogenous hemochromatosis and diabetes, and a living paternal uncle is also so affected. More precisely, since no pathologic organ function or morphology was demonstrable, he is classified as being at a prehemochromatotic stage of endogenous hemochromatosis (24). 


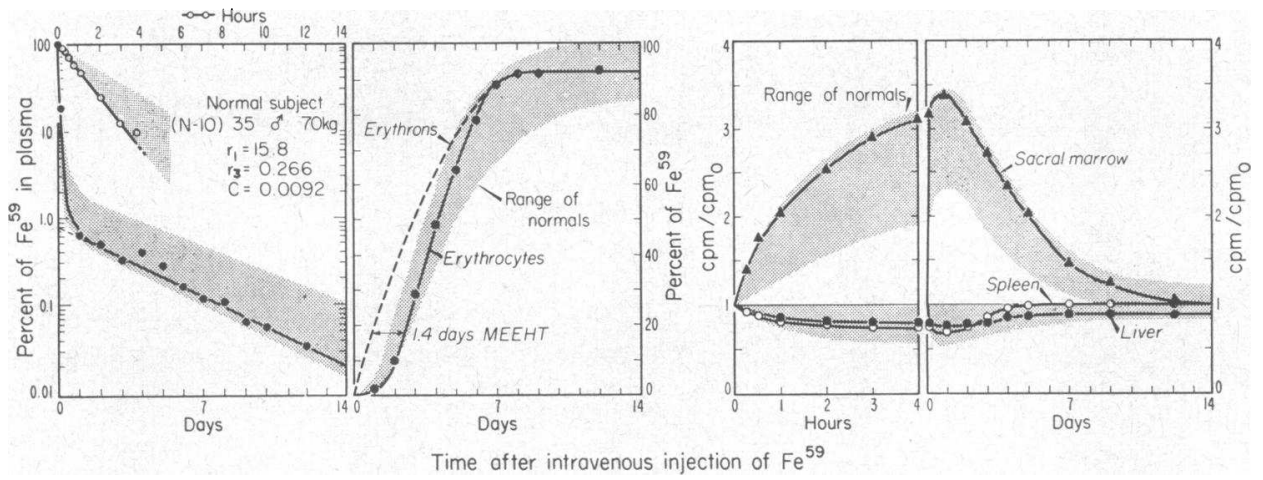

Fig. 1. Radioiron in Plasma and eRythrocytes, and SURface Radioactivity in a NORMal SUBJECT. The interrupted curve, showing cumulative fixation of radioiron in erythrons, and the mean effective erythron hemoglobinization time (MEEHT) are calculated as shown in Appendices $\mathrm{C}$ and $\mathrm{D}$.

Ten to $40 \mu \mathrm{c}$ of radioactive iron $\left(\mathrm{Fe}^{50}\right)$, as ferrous citrate or ferric ammonium citrate, specific activity 1 to 15 $\mu \mathrm{c}$ per $\mu \mathrm{g}$, was used. This was added to sufficient fresh plasma (the recipient's plasma is used except when it lacks sufficient latent iron-binding capacity) to ensure binding of all iron to the $\beta_{1}$-globulin, transferrin. After incubation at $37^{\circ} \mathrm{C}$ for 20 to 30 minutes, 5 to 20 $\mathrm{ml}$ of the labeled fresh plasma was injected intravenously with a calibrated syringe. Since iron in the plasma is entirely bound to transferrin, iron was injected in this form to ensure its acting as a true tracer. Others have given radioiron directly by i.v. injection and report that this mode of administration is satisfactory $(10,25)$. Perhaps radioiron may be used in this way as a tracer if given slowly so as not to exceed the plasma iron-binding capacity of the small mixing volume in transit from the site of injection to the lungs. During the 10 to 14 days following injection, serial blood samples were analyzed for plasma and erythrocyte radioactivity, and surface measurements of radioactivity over liver, spleen, and sacral bone marrow were made.

Plasma and erythrocyte radioactivity were measured by counting 2- or 3-ml samples in a well scintillation counter, with a 2 -inch $\mathrm{NaI}$ crystal and 6-inch lead shielding (26). The counting efficiency was about 25 per cent for $\mathrm{Fe}^{50}$ and the background approximately $105 \mathrm{cpm}$. Blood samples were centrifuged at $2,000 \mathrm{G}$ for $15 \mathrm{~min}$ utes to obtain plasma free of erythrocytes. It was necessary to take care in drawing and manipulating the blood to avoid hemolysis which, after significant labeling of erythrocytes occurs, would produce erroneously high concentration of radioiron in plasma (Figure 14, N-9). Concentration of iron in plasma and latent iron-binding capacity were determined by the modification of Peters and co-workers of the Ramsey method (27). Hematocrits were determined on all samples. Plasma and red cell volumes were determined independently by the $\mathrm{Fe}^{59}$ and $\mathrm{P}^{32}$ dilution methods $(28,29)$. Surface counting rates were obtained from mobile scintillation counters over liver and spleen, angled posteriorly from the anterior and midaxillary lines, respectively, and in the posterior midline over the broad upper portion of the sacrum as shown in Figures 21 and 22 in Appendix F $(2,3)$. A counting rate was also obtained over the anterior aspect of the thigh at a level $12 \mathrm{~cm}$ above the upper border of the patella. This position at the lower end of the femur is

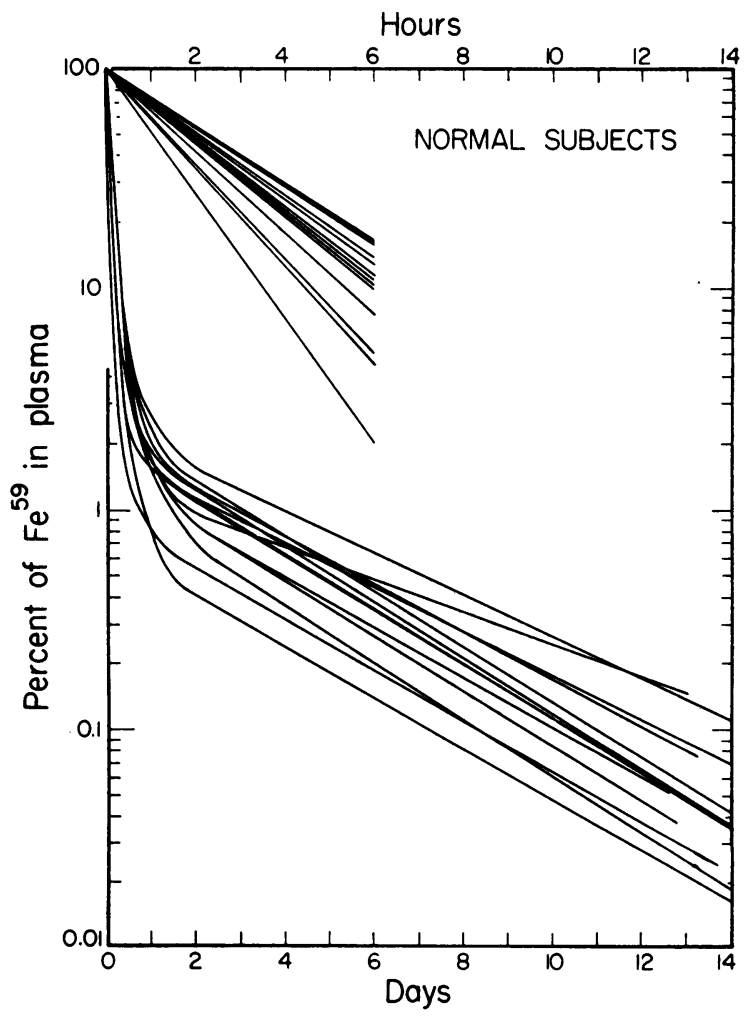

Fig. 2. Per cent of radioiron in plasma after inTRAVENOUS INJECTION, SHOWING RAPID AND SLOW EXPONential Components. Plasma radioiron data in 3 representative normal subjects are shown in Figure 14. 


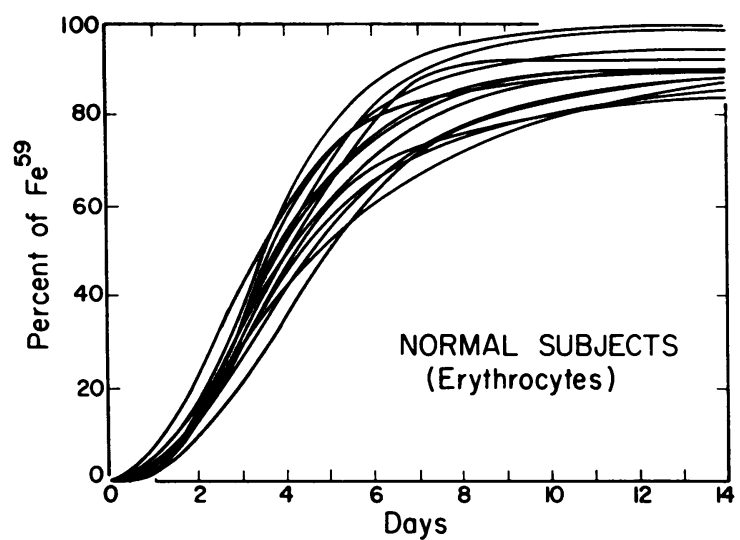

Fig. 3. Per cent of radioiron in circulating Red cell MASS AFTER INTRAVENOUS INJECTION.

used to detect increase of red marrow volume in adults and to check variation of background and instrumentation.

\section{MATHEMATICAL ANALYSIS OF PLASMA RADIOIRON}

Study of normal subjects for whom tracer radioiron was measured in plasma, sacral marrow, liver, spleen, and circulating erythrocytes (Figures $1-4$ ), results in the following observations. Virtually all radioactive iron moves rapidly from plasma to bone marrow, remaining there longer than 1 day. During the next 4 to 6 days, radioiron leaves the marrow and simultaneously appears within circulating erythrocytes. In plasma, dur-
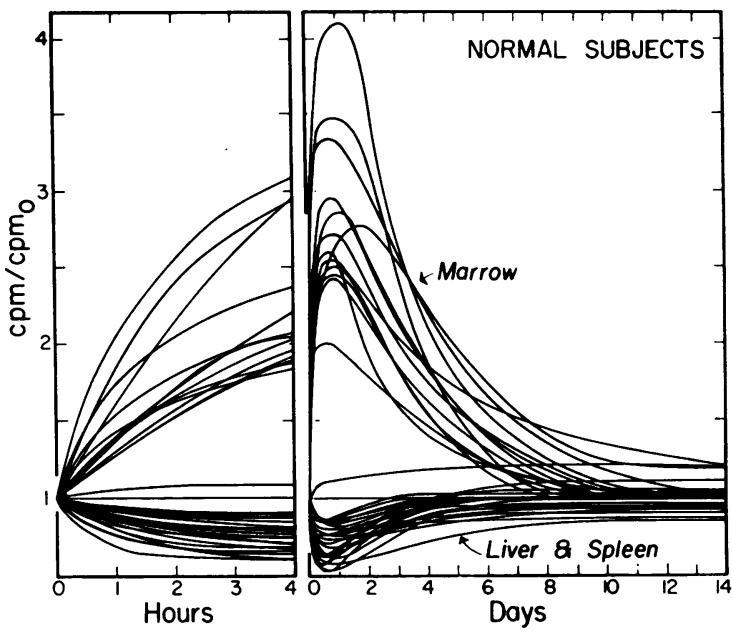

Fig. 4. Ratios of Sacral, hepatic, and splenic surFACE COUNTING RATES TO INITIAL RATE AFTER INTRAVENOUS INJECTION OF RADIOIRON.

ing the first 5 to 8 hours, there is a rapid exponential decrease of radioiron, the rate of which subsequently diminishes. After approximately 2 days, a second, slower exponential rate of decrease of radioiron is established. This persists for 8 to 12 days (Figures 1,2 ). The presence of this second component is evidence for feedback of radioactive iron into plasma from another iron pool. Since virtually all plasma radioiron transfers to marrow, it seems plausible that the feedback occurs from marrow. It can be shown that, if most of the radioiron feedback were to occur from a labile storage pool rather

Iron kinetics model - negligible storage exchange

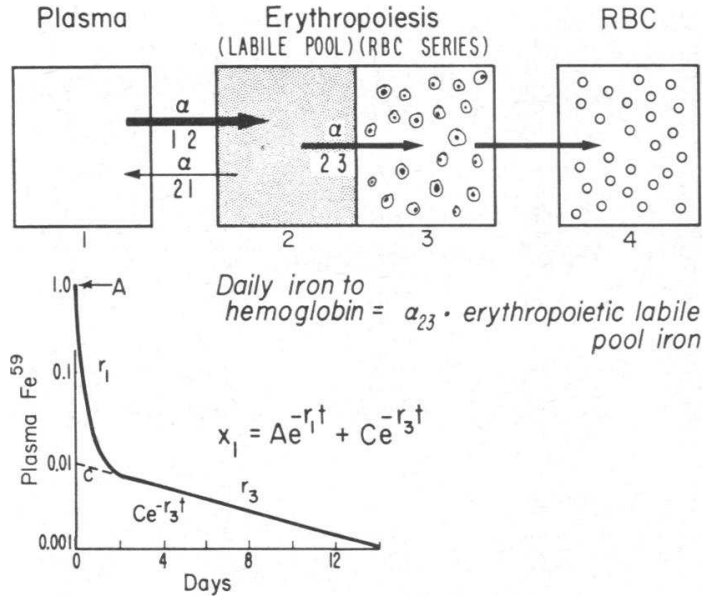

a.) "Normal"

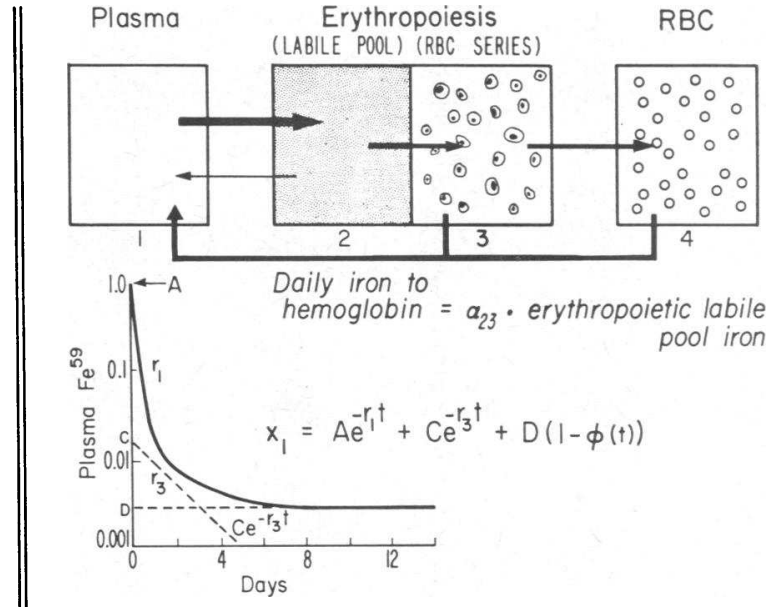

b.) "Hemolytic"

Fig. 5. IRON KINETICS MODEL PROPOSED TO APPLY UNDER CONDITIONS OF NEGLIGIBLE PLASMA-STORAGE IRON EXCHANGE AND SOLUTION OF THE CORRESPONDING DIFFERENTIAL EQUATIONS. In the absence of hemolysis, plasma radioiron continues to decrease exponentially for 2 weeks. Hemolysis of maturing erythrons or circulating erythrocytes results in feedback of radioiron to plasma and early equilibration of plasma radioiron at a constant level. 


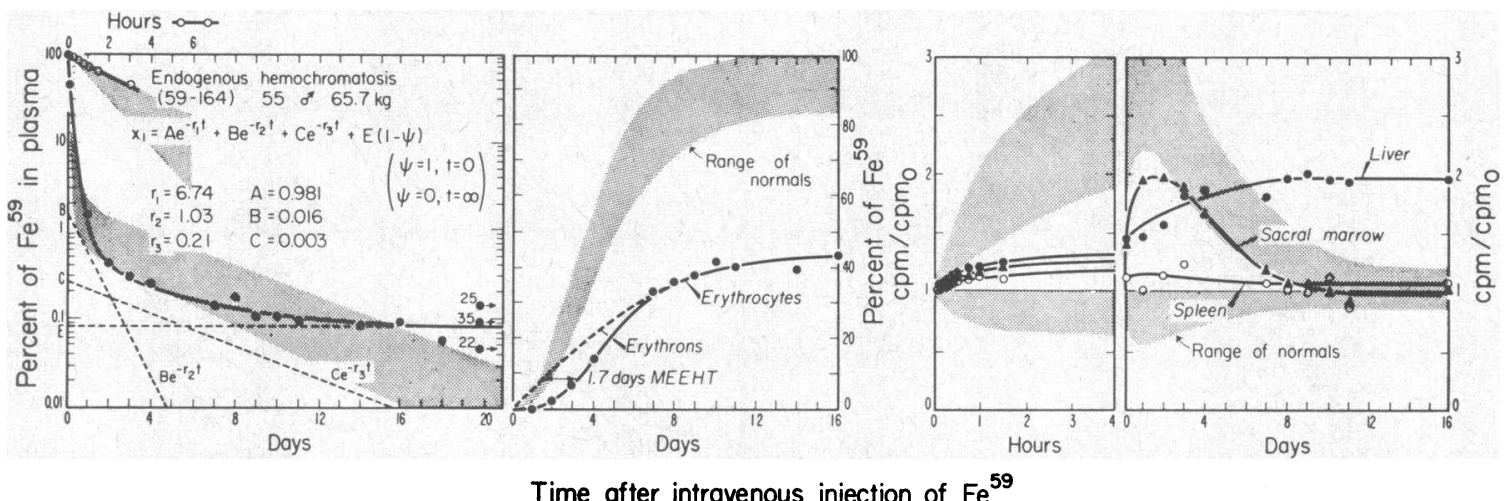

Time after intravenous injection of $\mathrm{Fe}^{59}$

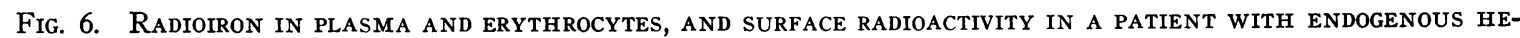
Mochromatosis. The interrupted curve, showing cumulative fixation of radioiron in erythrons, and the MEEHT are calculated as shown in Appendices $\mathrm{C}$ and $\mathrm{D}$.

than a labile erythropoietic pool, most of the radioiron would transfer initially into the former instead of the latter pool and, since almost half of storage iron is in liver (30), would thereby markedly increase the hepatic counting rate. Reappearance in plasma of measurable radioactive iron from destroyed circulating erythrocytes and storage depots is normally delayed beyond the 10 to 14 day period of measurement.

From these considerations the model in Figure $5 \mathrm{a}$ is proposed for normal subjects whenever storage deposition is a very small fraction of plasma iron exchange. Solution of the corresponding simultaneous differential equations is presented in Appendix A. The plasma radioiron can be expressed as a function of time by the equation $x_{1}=A e^{-r_{1} t}+C e^{-r_{3} t}$. The slope $r_{1}$ is determined largely by the rate of transfer of radioiron from plasma into the labile erythropoietic iron pool (fraction of plasma iron transferred daily); the slope $r_{3}$ is determined largely by the rate of transfer of radioiron from the labile erythropoietic iron pool into maturing erythrons (fraction of

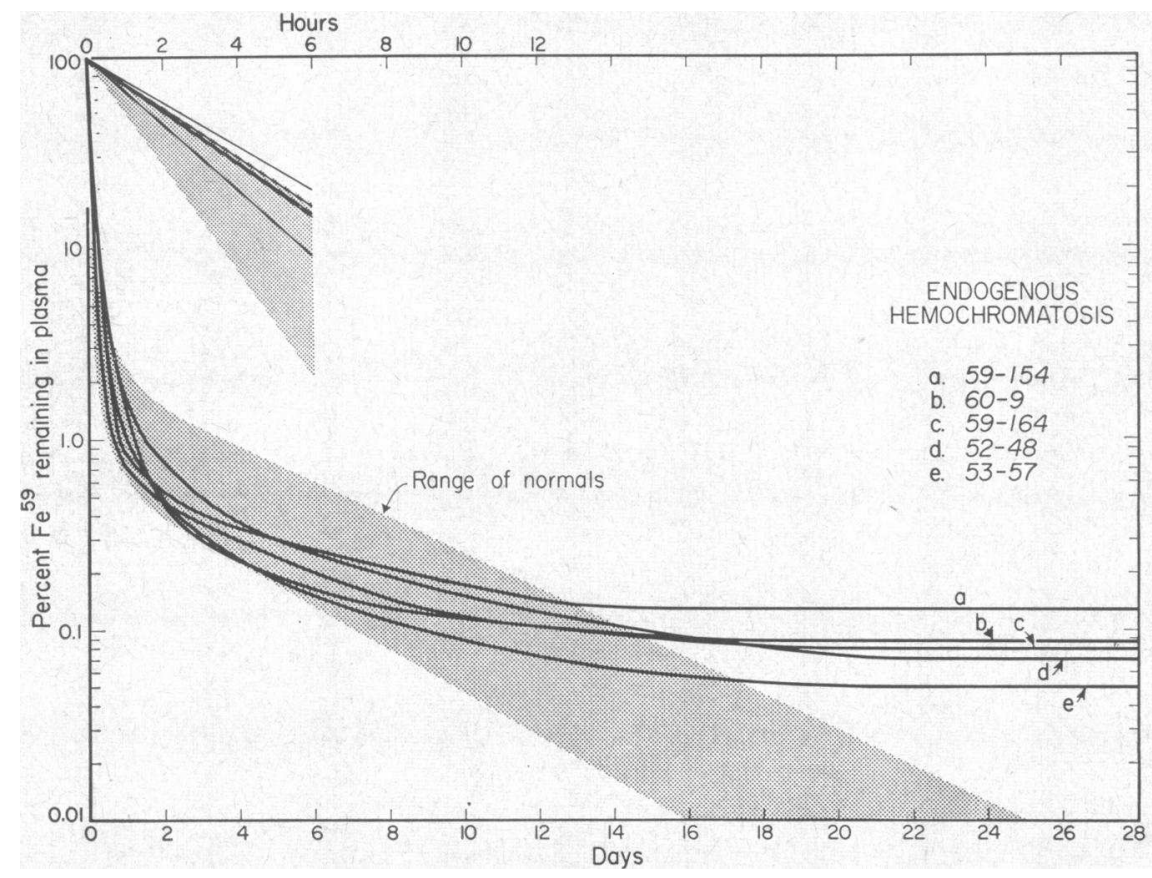

Fig. 7. Per CENT of Radioiron in PLASMa After intravenous injection, ShowING INITIAL RAPID EXPONENTIAL COMPONENT AND FINAL CONSTANT EQUILIBRIUM LEVEL. Graphic analysis reveals two additional exponential components (Figure 10). Plasma radioiron data in 3 representative patients with endogenous hemochromatosis are shown in Figure 10. 


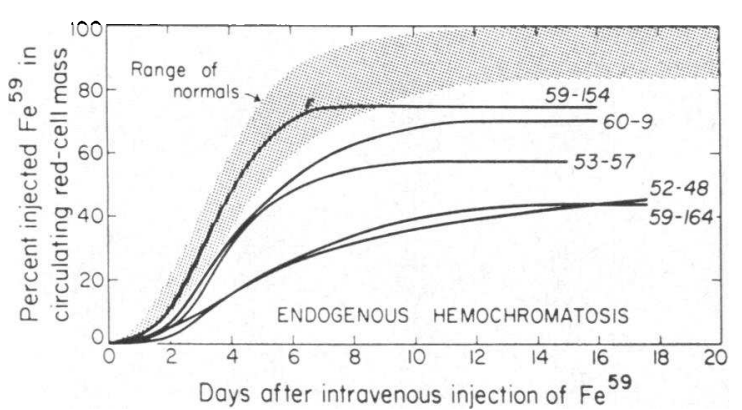

Fig. 8. Per cent of radioiron in circulating Red Cell MASS AFTER INTRAVENOUS INJECTION.

erythropoietic pool transferred daily). Measurement of the two plasma radioiron slopes and their intercepts, together with use of the formulae summarized in Appendix $\mathrm{D}$, permits calculation of the intercompartmental rate constants and the amount of iron in the labile erythropoietic pool. Calculation of the rates of irreversible iron fixation in maturing erythrons and the corresponding rates of hemoglobin synthesis is shown in Appendix B.

When considerable storage deposition of plasma iron occurs (as in patients with hemochromatosis, hemosiderosis, or decreased erythropoiesis) the model shown in Figure 5 is not adequate. Under these circumstances, initial hepatic deposition of radioiron occurs along with transfer to marrow and erythrons, and there is a corresponding decrease in the percentage of radioiron in-

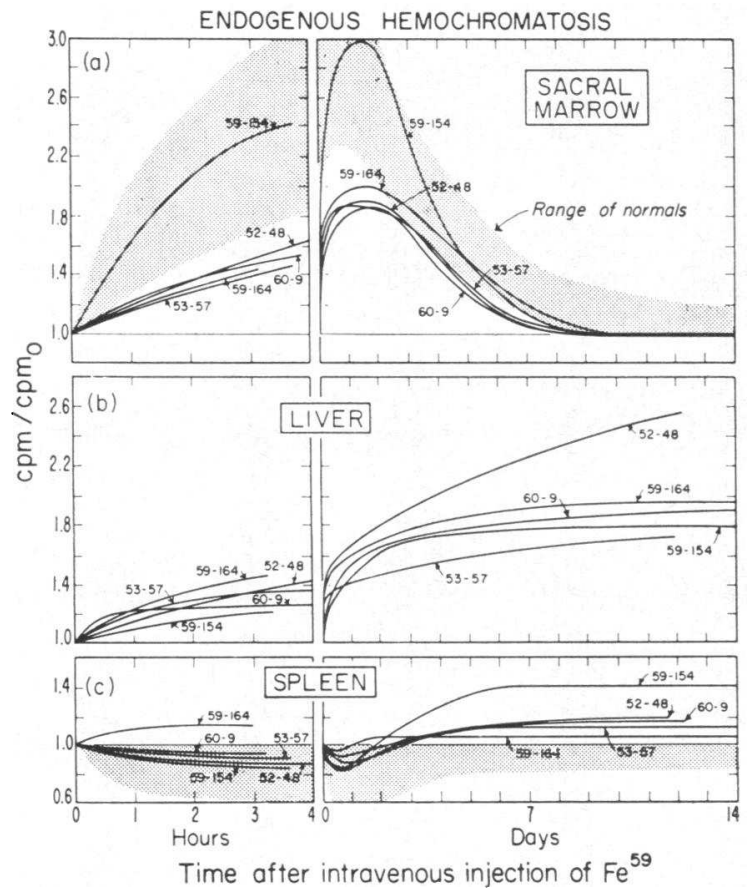

Fig. 9. Ratios of SACral, hepatic, and SPlenic SURFACE COUNTING RATES TO INITIAL RATE AFTER INTRAVENOUS IN JECTION OF RADIOIRON. corporated into circulating erythrocytes (Figures 6, 8, 9). This indicates that deposition of iron in relatively fixed stores occurs simultaneously with incorporation of iron from labile marrow pool into maturing erythrons (Figure 6). Graphic analysis of the plasma radioiron curve reveals distinctly more than two exponential components (Figure 10) which may be arbitrarily resolved into three exponential components. This pattern suggests feedback of radioiron from at least two distinct iron pools into the plasma pool. Under these circumstances, it is postulated that plasma iron exchanges with a storage pool in addition to an erythropoietic pool.

From these considerations the generally applicable

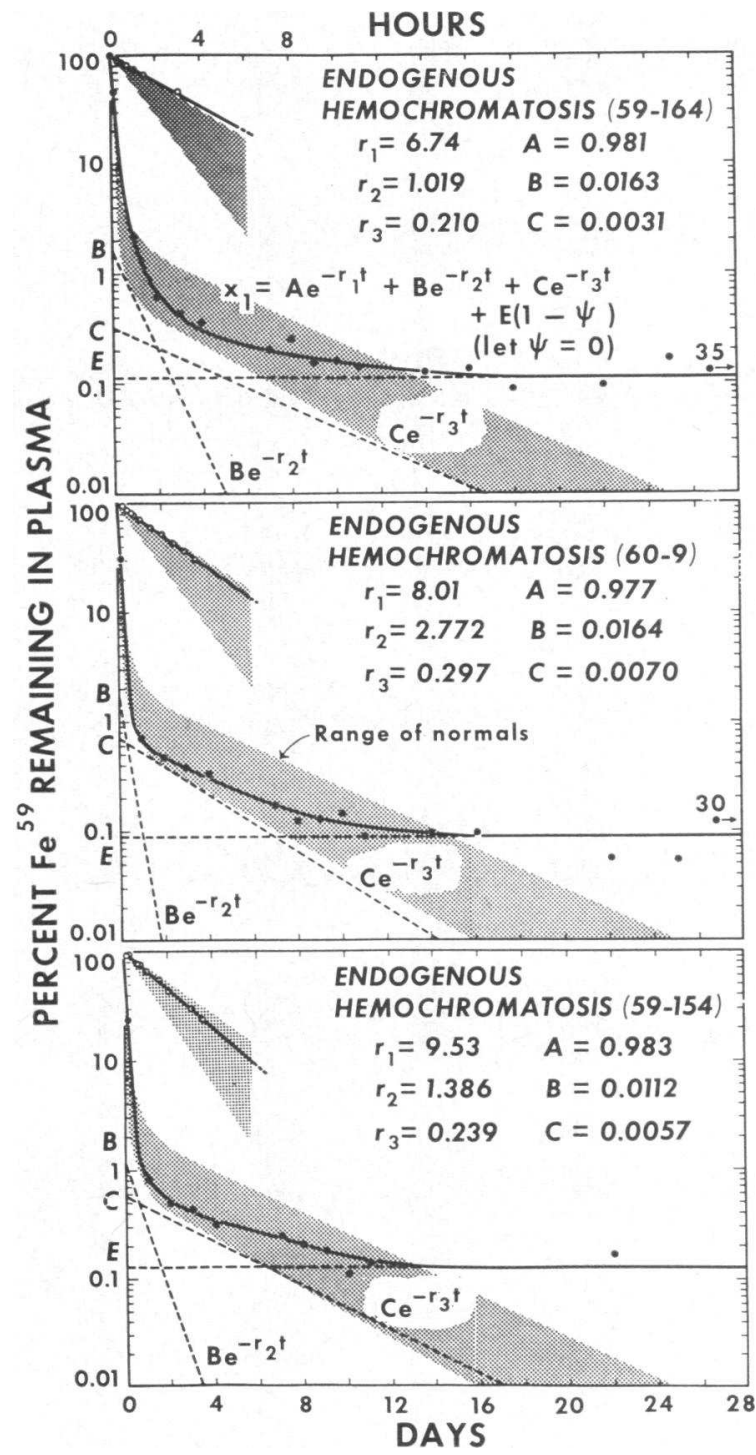

Fig. 10. Per Cent of Radioiron in Plasma AFTer INtravenous injection. Plasma radioiron data in 3 representative patients with endogenous hemochromatosis are shown. 
model shown in Figure 11 is proposed. Neglecting the slow return to plasma of iron from storage reserve, solution of the corresponding simultaneous differential equations is presented in Appendix A. The plasma radioiron can be expressed as the sum of three exponential components, $x_{1}=A e^{-r_{1} t}+B e^{-r_{2} t}+C e^{-r_{s} t}$. The magnitude of the slopes $r_{1}$ and $r_{3}$ corresponds to those observed for normal subjects. The additional slope observed when appreciable storage deposition of plasma iron occurs, $r_{2}$, is largely determined by the rate of transfer of radioiron from the labile storage pool into relatively fixed iron stores (fraction of storage pool transferred daily); it is considerably smaller than $r_{1}$ and larger than $r_{3}$. Slope $r_{3}$ is determined by irreversible transfer of iron from the labile erythropoietic pool into erythrons. Measurement of the three plasma radioiron slopes, their intercepts, and $f$, the maximal fraction of radioiron incorporated into erythrons, together with the use of the formulae summarized in Appendix D, permits calculation of the amounts of iron in the labile erythropoietic and labile storage pools. Calculation of the rates of iron deposition in stores, irreversible fixation of iron in maturing eryth- rons, and corresponding hemoglobin synthesis is shown in Appendix B. The simple model is seen to be a special case of the more general storage model when $\alpha_{15}=0$.

The rate of hemoglobin synthesis can be calculated from the daily amount of iron fixed irreversibly in maturing erythrons, using the relation: $1 \mathrm{~g}$ hemoglobin contains $3.4 \mathrm{mg}$ iron. This involves the assumption that the iron present in mature erythrocytes is almost entirely in hemoglobin. The calculation of hemoglobin synthesis involves measurement of the initial slope, $r_{1}$, and total plasma iron, $X_{1}$, measured during the initial 4 hour period of study. The assumption of steady state conditions implies that the initial plasma iron turnover, $\alpha_{12} X_{1}$, is equal to the average turnover during the 2 week period of study. The concentration of iron in plasma of normal subjects varies daily, being approximately 15 per cent less at the end of the day before sleep than at the beginning of day after rising $(31,32)$. Plasma iron turnover, however, is probably more constant, since this is almost entirely determined by the number of erythrons and storage iron present. Plasma iron turnover in normal subjects is relatively constant throughout the wide range

Iron kinetics model-storage exchange

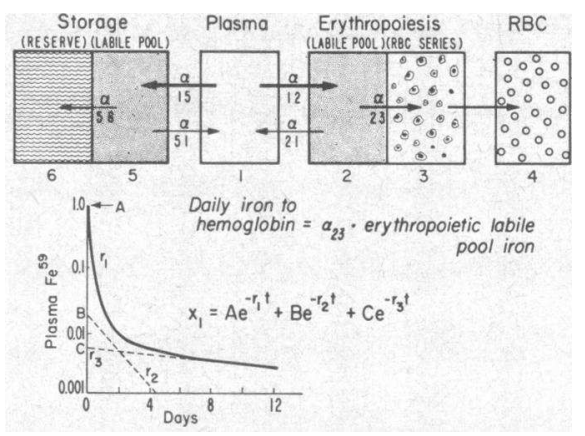

o.) "Normal"
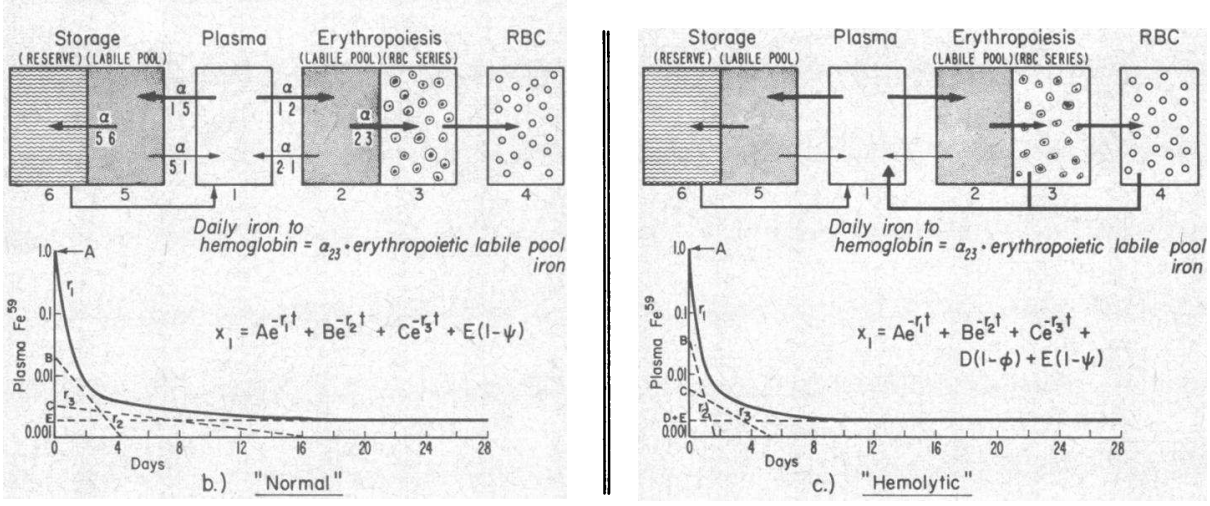

Fig. 11. IRON Kinetics MODEL PROPOSED TO INCLUde PLASMA-STORAGE IRON EXCHANGE AND SOLUTION OF THE CORRESPONDING DIFFERENTIAL EQUATIONS. In the absence of hemolysis, plasma radioiron slowly equilibrates at a constant level after 2 weeks as a result of slow feedback of radioiron to plasma from the miscible reserve storage iron pool. Hemolysis of maturing erythrons or circulating erythrocytes results in more rapid feedback of radioiron to plasma and early equilibration of plasma radioiron at a constant level. 
of plasma iron concentration of 70 to $170 \mu \mathrm{g}$ per $100 \mathrm{ml}$, the fraction of plasma iron removed per hour increasing as total plasma iron decreases, thereby maintaining a constant product.

The mean life span of the erythron is estimated by the ratio of total hemoglobin to daily hemoglobin breakdown. The latter is calculated from the rate of hemoglobin synthesis and the change, if any, in total hemoglobin (Appendix B). The calculation of mean erythron life span involves the assumption that the average rate of hemoglobin breakdown, calculated from measurements during a 2 week period, remains constant during the life span of the erythron. Mean erythron life span in this context signifies the life span corresponding to the calculated average rate of hemoglobin breakdown. The mean time interval between incorporation of iron into marrow erythrons and its appearance in circulating erythrocytes is designated as the mean effective erythron hemoglobinization time (MEEHT). The method of calculating cumulative net incorporation of radioiron into maturing erythrons and MEEHT is presented in Appendix C. The simpler mathematical model (Figure 5) in which plasma iron exchange with storage pools is neglected can be applied, not only to normal subjects, but to a variety of conditions in which the normal pattern of iron flow from plasma to marrow to erythrocytes occurs. This includes iron deficiency anemia, primary or secondary polycythemia, and most hemolytic anemias (21, $22,33,34)$. Premature re-entry of radioiron into plasma results whenever erythron hemolysis occurs, whether in marrow (associated with increased MEEHT) or subsequent to erythron entry into the circulation [frequently associated with delayed increase of splenic counting rate above its initial level; i.e., cpm per $\mathrm{cpm}_{0}>1$ (22)]. In hemolytic anemias, feedback of radioiron from destroyed labeled erythrocytes to plasma results in a progressive decrease of the negative plasma radioiron slope (which may even become positive in severe hemolysis), terminating in a constant equilibrium level (22). Under these circumstances, the exponential components may be approximated by subtraction of the minimal value from the preceding curve.

This mathematical treatment of hemolytic feedback is a simple approximation that is very useful and yields results that agree closely with more complex and precise methods. The approach is not rigorous, since it is apparent that feedback of radioiron from hemolyzed erythrons to plasma is not present at a constant level from time of injection through the entire 2 week period of study. Detailed analysis of this problem, with evaluation of the hemolytic component will be presented separately, together with results obtained in studies of patients with hemolytic anemias (21). The term $D[1-$ $\phi(t)], \phi(t)=1$ at $t=0$ and $\phi(t)=0$ at $t=\infty$ (Figures $5,11)$ represents the component of plasma radioiron resulting from hemolysis. A simple approximation is obtained by setting $\phi(t)=0, D$ being the measured final constant value of plasma radioiron. This simplification alters the calculated rate of hemoglobin synthesis and derived mean erythron life span by less than 10 per cent, as compared with values derived from use of $D[1-\phi(t)]$.

Feedback of radioiron from relatively fixed stores to plasma becomes appreciable in 14 to 21 days. Considerations similar to those discussed for hemolytic feedback apply, and $x_{1}=A e^{-r_{1} t}+B e^{-r_{2} t}+C e^{-r_{3} t}+E[1-\psi(t)]$ (Figure 11b). Since the final "constant" plasma radioiron level $E$, resulting from storage feedback, usually occurs at a later time and a lower level than that resulting from hemolytic feedback, a smaller error (less than 5 per cent) is introduced by subtracting this constant minimal value from the preceding curve. A more rigorous and complex mathematical treatment of feedback from relatively fixed stores (compartment 6 illustrated in Figure 6) will be presented separately. The amount of storage iron that is miscible in approximately 3 weeks is calculated by relating the "constant" plasma radioiron level $E$ to the fraction of injected radioiron deposited in storage, $1-f$, as shown in Appendix B. In the absence of hemolysis, radioiron continues to be slowly removed from storage reserve and is incorporated via plasma into circulating erythrocytes. The so-called constant plasma level $E$ is, in fact, a slowly decreasing one, but with too shallow a slope to be evident during the 4 to 5 week period of observations.

All radioiron is initially in plasma, and 7 to 10 days later is normally almost entirely in circulating erythrocytes. Initial surface radioactivity rates over liver, spleen, and marrow, $\mathrm{cpm}_{0}$, obtained by extrapolation back to $t=$ 0 , are largely the result of radioactivity in plasma circulating through these organs. As radioiron leaves plasma and accumulates in marrow, splenic and hepatic counting rates usually fall, while the sacral counting rate rises rapidly. Subsequently, in vivo counting rates normally return to their initial value, $\mathrm{cpm}_{0}$, when almost all radioiron has returned to the blood (Figures 1, 4). For convenience, body surface radioactivity is not expressed as net radioactivity, $\mathrm{cpm}-\mathrm{cpm}_{0} \times$ (fraction of radioiron in circulating blood), but rather as the ratio $\mathrm{cpm} / \mathrm{cpm}_{0}$. Expressed in this way, hepatic and splenic radioactivity normally do not exceed 1 , sacral radioactivity usually exceeds 2 within 4 hours, and all sites approximate 1 within 10 days (Figure 4). Slow increase of surface hepatic radioactivity during the first 3 hours after injection, together with simultaneous slow disappearance of radioiron from plasma (small $r_{1}$ ), is almost always the result of considerable iron exchange between plasma and stores (Figures 6, 7, 9); while relatively rapid initial hepatic accumulation of radioiron, comparable with the rate of normal sacral accumulation of radioiron, is associated with hemoglobin synthesis in hepatic erythrons and subsequent decrease of hepatic radioactivity $(2,21$, 22). Slow initial increase of hepatic radioactivity (not present in patients with low concentration of iron in plasma) with confirmatory presence of a distinct third exponential component in the plasma radioiron curve, and subnormal incorporation of radioiron into circulating erythrocytes, indicates application of the storage ex- 
change model (Figure 11). Unless there is gradual initial increase of hepatic radioactivity that persists (Figure 9), the "normal flow" model is used (Figure 5). In so neglecting normal storage iron deposition, not more than a 10 per cent error is incurred in calculating hemoglobin synthesis and mean erythron life span, as shown in the Discussion. Because of the experimental error ( \pm 5 per cent $)$ involved in red cell volume determinations used to determine $f$, it does not seem advantageous to use the storage exchange model for more exact measurement of normal deposition of stored plasma iron.

The storage exchange model involves the variable $f$, the maximal fraction of injected radioiron incorporated into erythrons. When hemolysis is absent, as is the case in 5 of the patients with hemochromatosis, $f$ equals the measured maximal incorporation of radioiron into circulating erythrocytes (Figures 6 and 8). If erythrons are destroyed within the 10 day period after incorporation of radioiron, then $f$ is greater than maximal net incorporation of radioiron into circulating erythrocytes. The occurrence of hemolysis usually is evidenced by cessation of the decrease in plasma radioiron and establishment of a constant equilibrium level in 10 days or less $(21,22$, 34). Plasma radioiron would not be expected to reach a constant level in less than 10 days whenever hemolysis is solely the result of a shortened finite erythrocyte life span longer than 10 days. Finite erythrocyte life span is here defined as the occurrence of erythrocyte destruction with normal distribution about a definite time interval after erythron release into the circulation. Occurrence of only this type of hemolysis is probably rare, since complete study of over 400 patients with shortened erythrocyte life span has demonstrated equilibration of plasma radioiron at a constant level within 10 days (21).

This early stabilization of plasma radioiron is present in this study only in hemochromatotic Patient 59-70 with mild hemolysis resulting in a mean erythron life span of 52 days; plasma radioiron in this patient attains a constant level by Day 9 (Figure 12). In this case $f$ is greater than maximal erythrocyte net incorporation of radioiron (Figure 12). To arrive at an estimate of $f$ when significant hemolysis and plasma-storage iron exchange are both present, surface measurements may be used as shown in Appendix E. Measurements of radioiron in liver, spleen, marrow, blood, and occasionally lung, are used in an effort to account in rough approximation for the distribution of radioiron in the body throughout the study. With rare exceptions it has been possible to do this in over 400 studies, including cases in which there is loss of radioiron by gastrointestinal bleeding or pulmonary bleeding $(21,28)$. These semiquantitative estimates derived from surface counting allow better localization and quantitation of pathologic function and are helpful in selecting the appropriate model and value for $f$ used for quantitative analysis of plasma and erythrocyte radioiron data (Appendix E). Most patients with appreciable hemolysis, however, do not have appreciable plasma-storage iron exchange relative to plasma-erythropoiesis iron exchange, and the "normal flow" model is used-i.e., $f=1$.

When the storage exchange model involving the sum of three exponentials is used, the slopes and intercepts obtained from the plasma radioiron curves are quite sensitive to the curve-fitting employed. Although the values for compartment size and transfer rate are very sensitive to errors in the graphically determined slopes and intercepts, these changes are compensatory with respect to the amounts of iron transferred. For example, if at a given level of plasma radioiron, $r_{3}$ becomes greater, $C$ also becomes larger, the calculated erythropoietic labile pool $\left(X_{2}\right)$ smaller, and the rate constants $\alpha_{23}$ and $\alpha_{21}$ become larger; the products $\alpha_{23} X_{2}$ (iron fixed for hemoglobin synthesis) and $\alpha_{21} X_{2}$ (iron feedback to plasma), however, remain relatively constant. Measurement of the rate of appearance of radioiron in circulating erythrocytes is very useful as an independent rough check of the applicability of the calculated transfer rate from the erythropoietic labile pool compartment $\left(X_{2}\right)$ to the fixed erythron iron compartment $\left(X_{3}\right)$. This transfer rate into erythrons must be more rapid than the emergence

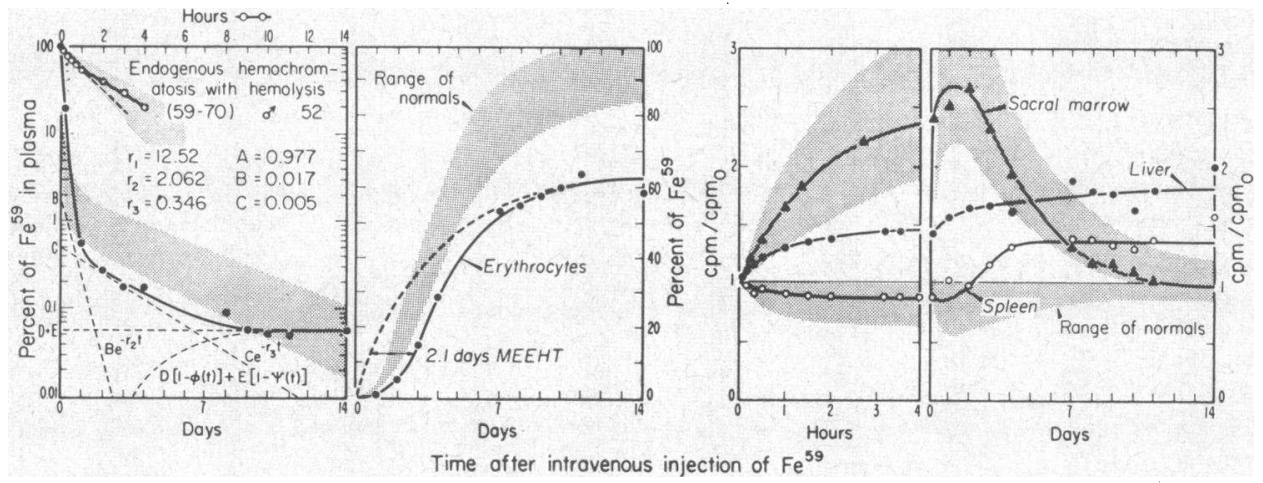

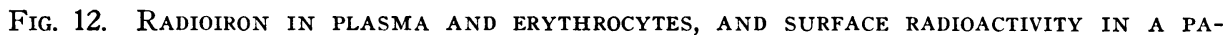
TIENT WITH ENDOGENOUS HEMOCHROMATOSIS AND MILD HEMOLYSis. Plasma radioiron stabilizes at a constant level within 9 days as a result of the hemolytic component $D[1-\phi(t)]$ superimposed upon the more gradual storage feedback component $E[1-\psi(t)]$. 


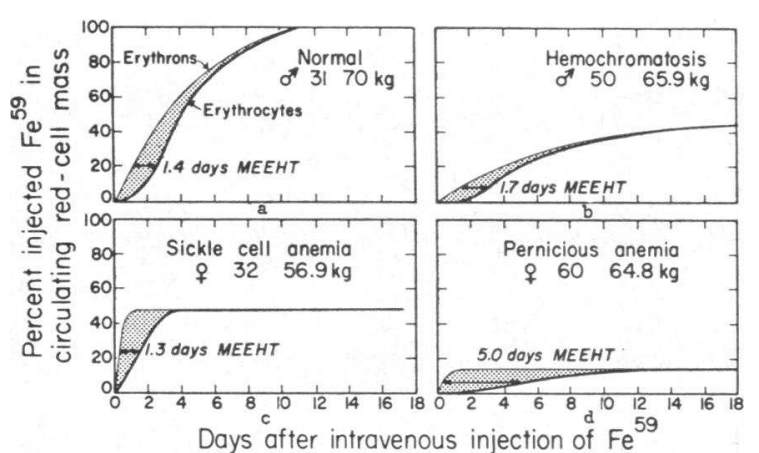

Fig. 13. Cumulative net incorporation of radioIRON INTO ERYTHRONS AND CIRCULATING ERYTHROCYTES AND MEEHT. See Appendix C.

of radioiron in circulating erythrocytes (Figures 1, 6, 12, 13). Because of random errors in plasma data obtained at very low levels of radioactivity and errors involved in determining $f, D(1-\phi)$, and $E(1-\psi)$, analysis of the plasma curve must be integrated with measurements of red cell, marrow, liver, and spleen radioiron to obtain the most accurate and meaningful results.

\section{RESULTS}

Results obtained in 13 normal subjects are shown in Table I. These include experimental data obtained by direct measurements and calculated intercompartmental rate constants, labile erythropoietic iron pool size, daily hemoglobin synthesis, mean erythrocyte life span, and mean effective erythron hemoglobinization time. The plasma radioiron curves of this group can be resolved into two exponential components (Figures $1,2,14)$. Using these slopes and their intercepts, the following average estimates are obtained in normal subjects: $32.5 \mathrm{mg}$ of iron leaves plasma daily $\left(\alpha_{12} X_{1}\right)$. Of this, $21.4 \mathrm{mg}\left(\alpha_{23} X_{2}\right)$-i.e., approximately two-thirds, or $\alpha_{23} /\left(\alpha_{23}+\alpha_{21}\right)$-is used for daily hemoglobin synthesis. Expressed in another way, the daily feedback of iron, $11.1 \mathrm{mg}$ $\left(\alpha_{21} X_{2}\right)$, from the labile erythropoietic pool $\left(X_{2}\right)$, mean value $84.9 \mathrm{mg}$, to plasma pool $\left(X_{1}\right)$, mean value $3.6 \mathrm{mg}$, is approximately one-third, $\alpha_{21} /\left(\alpha_{23}+\alpha_{21}\right)$, of the amount of iron, $32.5 \mathrm{mg}$, daily entering the labile erythropoietic pool from plasma. Normal daily hemoglobin synthesis is $6.3 \pm 0.9$ ( $1 \mathrm{SD}$ ) g per day ( 55 to $84 \mathrm{~kg}$, weight range) or $1.3 \pm 0.2 \mathrm{~g}$ per $\mathrm{L}$ blood per day. Assuming a steady state, verified during the course of each individual studied, we calculate a mean erythrocyte life span of $117 \pm 7.5$ days. The esti-

TABLE I

Data derived from normal subjects

\begin{tabular}{|c|c|c|c|c|c|c|c|c|c|c|c|c|c|c|}
\hline Subject & $\underset{W t}{A g e, ~} S$ & $\begin{array}{l}\text { Sex, } \\
t\end{array}$ & $\mathrm{Hb}$ & Hct & MCHC* & $\mathrm{RCV} \dagger$ & $\begin{array}{l}\text { Total } \\
\text { body } \\
\text { Hb }\end{array}$ & $t_{\frac{1}{2}}$ & SI & BV & PV & $\begin{array}{c}\text { Total } \\
\text { plasma } \\
\text { iron } \\
X_{1}\end{array}$ & $\begin{array}{c}\text { First } \\
\text { plasma } \\
\mathrm{Fe}^{59} \\
\text { slope } \\
r_{1}\end{array}$ & $\begin{array}{c}\text { Second } \\
\text { plasma } \\
\mathrm{Fe}^{59} \\
\text { slope } \\
r_{3}\end{array}$ \\
\hline & $y r s$ & $\mathrm{~kg}$ & $100^{\prime} \mathrm{ml}$ & $\%$ & $\%$ & $m l$ & $g$ & hrs & $\stackrel{\mu g /}{100 \mathrm{ml}}$ & $m l$ & $m l$ & $\mathrm{mg}$ & & \\
\hline N- 1 & 629 & 75.0 & 14.0 & 42.4 & 0.33 & 1,540 & 509 & 2.25 & 101 & 4,140 & 2,600 & 2.6 & 7.4 & 0.289 \\
\hline N- 2 & $35 \sigma^{7}$ & 78.0 & 15.9 & 42.5 & 0.37 & 2,360 & 883 & 1.80 & 112 & 5,590 & 3,230 & 3.3 & 9.3 & 0.266 \\
\hline N- 3 & $28 \sigma^{7}$ & 66.8 & 15.4 & 44.0 & 0.35 & 2,090 & 731 & 1.83 & 144 & 4,750 & 2,660 & 4.2 & 9.1 & 0.289 \\
\hline N- 4 & $32 \sigma^{7}$ & 70.0 & 17.1 & 49.1 & 0.35 & 2,130 & 745 & 2.32 & 200 & 4,490 & 2,360 & 4.7 & 7.2 & 0.289 \\
\hline N- 5 & $29 \sigma^{7}$ & 84.0 & 14.5 & 44.0 & 0.33 & 2,180 & 928 & 1.60 & 117 & 5,780 & 2,970 & 3.5 & 10.4 & 0.306 \\
\hline N- 6 & $260^{7}$ & 75.0 & 15.2 & 44.9 & 0.34 & 2,180 & 741 & 2.28 & 150 & 5,000 & 2,820 & 4.2 & 7.3 & 0.231 \\
\hline N- 7 & $26 \sigma^{7}$ & 77.0 & 14.0 & 45.0 & 0.31 & 2,410 & 749 & 1.89 & 119 & 5,360 & 2,950 & 3.8 & 9.0 & 0238 \\
\hline N- 8 & $32 \sigma^{7}$ & 68.2 & 15.0 & 46.9 & 0.32 & 2,010 & 643 & 2.00 & 130 & 4,460 & 2,450 & 3.2 & 8.3 & 0.210 \\
\hline N -9 & $720^{7}$ & 75.0 & 17.5 & 50.0 & 0.35 & 2,070 & 725 & 2.10 & 185 & 4,340 & 2,270 & 4.2 & 7.9 & 0.239 \\
\hline$N-10$ & $35 \sigma^{x}$ & 69.5 & 14.8 & 45.0 & 0.33 & 2,280 & 750 & 1.05 & 74 & 5,550 & 3,220 & 2.4 & 15.8 & 0.266 \\
\hline N-11 & $24 \sigma^{7}$ & 63.5 & 16.2 & 48.0 & 0.34 & 2,310 & 785 & 1.62 & 160 & 4,940 & 2,630 & 4.2 & 10.3 & 0.167 \\
\hline $\mathrm{N}-12$ & 29 ד' & 72.7 & 14.1 & 44.6 & 0.32 & 2,350 & 751 & 1.35 & 86 & 5,730 & 3,380 & 2.9 & 12.3 & 0.289 \\
\hline \multirow[t]{3}{*}{$\mathrm{N}-13$} & $33 \sigma^{7}$ & 54.8 & 14.0 & 43.4 & 0.32 & 1,980 & 634 & 2.31 & 136 & 4,980 & 3,000 & 4.1 & 7.2 & 0.217 \\
\hline & Mean & 71.5 & 15.2 & 45.4 & 0.33 & 2,150 & 738 & 1.88 & 132 & 5,010 & 2,810 & 3.6 & 9.3 & 0.254 \\
\hline & SD & & & & & & \pm 99 & \pm 0.38 & \pm 35 & & & \pm 0.7 & \pm 2.4 & \pm 0.039 \\
\hline
\end{tabular}

* Mean corpuscular hemoglobin concentration.

$\dagger$ Red cell volume, 
TABLE I-(Continued)

\begin{tabular}{|c|c|c|c|c|c|c|c|c|c|c|c|}
\hline & \multirow{2}{*}{$\begin{array}{l}\text { Second } \\
\text { plasma } \\
\text { slope } \\
\text { inter- } \\
\text { cept } C\end{array}$} & \multicolumn{3}{|c|}{$\begin{array}{l}\text { Intercompartmental } \\
\text { rate constants }\end{array}$} & \multirow{2}{*}{$\begin{array}{c}F e \\
\text { leaving } \\
\text { plasma/ } \\
\text { day } \\
\boldsymbol{\alpha}_{12} X_{1}\end{array}$} & \multirow{2}{*}{$\begin{array}{c}\text { Erythro- } \\
\text { poietic } \\
\text { labile } \\
\text { iron } \\
\text { pool } \\
X_{2}\end{array}$} & \multirow{2}{*}{$\begin{array}{c}\text { Daily } \\
\text { Fe } \\
\text { for Hb } \\
\text { synthe- } \\
\text { sis } \\
\alpha_{28} X_{2}\end{array}$} & \multirow{2}{*}{\multicolumn{2}{|c|}{$\begin{array}{l}\text { Daily hemoglo- } \\
\text { bin synthesis }\end{array}$}} & \multirow[b]{2}{*}{ MELS† } & \multirow[b]{2}{*}{ MEEHT } \\
\hline & & $\alpha_{12}$ & $\alpha_{23}$ & $\alpha 21$ & & & & & & & \\
\hline Subject & & & & & $m g$ & $m g$ & $m g$ & $g$ & $g / L$ & days & days \\
\hline$N-1$ & 0.0220 & 7.30 & 0.293 & 0.094 & 19.2 & 49.5 & 14.5 & 4.3 & 1.0 & 108 & 1.5 \\
\hline N- 2 & 0.0070 & 9.19 & 0.268 & 0.061 & 30.3 & 92.1 & 24.7 & 7.3 & 1.3 & 121 & 1.4 \\
\hline N- 3 & 0.0200 & 8.91 & 0.295 & 0.170 & 37.4 & 80.4 & 23.8 & 7.0 & 1.5 & 105 & 1.4 \\
\hline N- 4 & 0.0244 & 7.02 & 0.296 & 0.161 & 33.2 & 72.6 & 21.5 & 6.3 & 1.4 & 118 & 1.6 \\
\hline N- 5 & 0.0120 & 10.28 & 0.309 & 0.118 & 36.0 & 83.0 & 25.6 & 7.5 & 1.3 & 124 & 1.1 \\
\hline N- 6 & 0.0180 & 7.20 & 0.235 & 0.105 & 30.2 & 88.9 & 20.9 & 6.2 & 1.2 & 120 & 1.4 \\
\hline N- 7 & 0.0200 & 8.83 & 0.242 & 0.171 & 33.5 & 81.2 & 19.7 & 5.8 & 1.1 & 129 & 1.3 \\
\hline N- 8 & 0.0110 & 8.24 & 0.222 & 0.077 & 26.2 & 86.1 & 19.1 & 5.6 & 1.3 & 115 & 1.4 \\
\hline N- 9 & 0.0180 & 7.79 & 0.244 & 0.133 & 32.7 & 86.7 & 21.2 & 6.2 & 1.4 & 117 & 1.3 \\
\hline $\mathrm{N}-10$ & 0.0092 & 15.66 & 0.268 & 0.141 & 37.4 & 91.4 & 24.5 & 7.2 & 1.4 & 104 & 1.6 \\
\hline $\mathrm{N}-11$ & 0.0130 & 10.17 & 0.169 & 0.130 & 42.7 & 143.0 & 24.2 & 7.1 & 1.4 & 111 & 1.1 \\
\hline $\mathrm{N}-12$ & 0.0153 & 12.11 & 0.293 & 0.180 & 35.1 & 74.2 & 21.8 & 6.4 & 1.1 & 117 & 1.6 \\
\hline $\mathrm{N}-13$ & 0.0240 & 7.04 & 0.222 & 0.163 & 28.8 & 74.9 & 16.6 & 4.9 & 1.0 & 129 & 1.7 \\
\hline Mean & 0.0165 & 9.21 & 0.258 & 0.131 & 32.5 & 84.9 & 21.4 & 6.3 & 1.3 & 117 & 1.4 \\
\hline SD & \pm 0.0054 & \pm 2.36 & \pm 0.039 & \pm 0.037 & \pm 5.7 & \pm 19.9 & \pm 3.2 & \pm 0.9 & \pm 0.2 & \pm 7.5 & \pm 0.2 \\
\hline
\end{tabular}

$\$$ Mean erythrocyte life span.
Mean effective erythron hemoglobinization time.

mated MEEHT is $1.4 \pm 0.2$ days. This quantity is a measure of the time interval between incorporation of iron into red cell precursors and its release into the vascular system.

Results obtained from six patients with en- iron storage deposition, miscible storage iron,

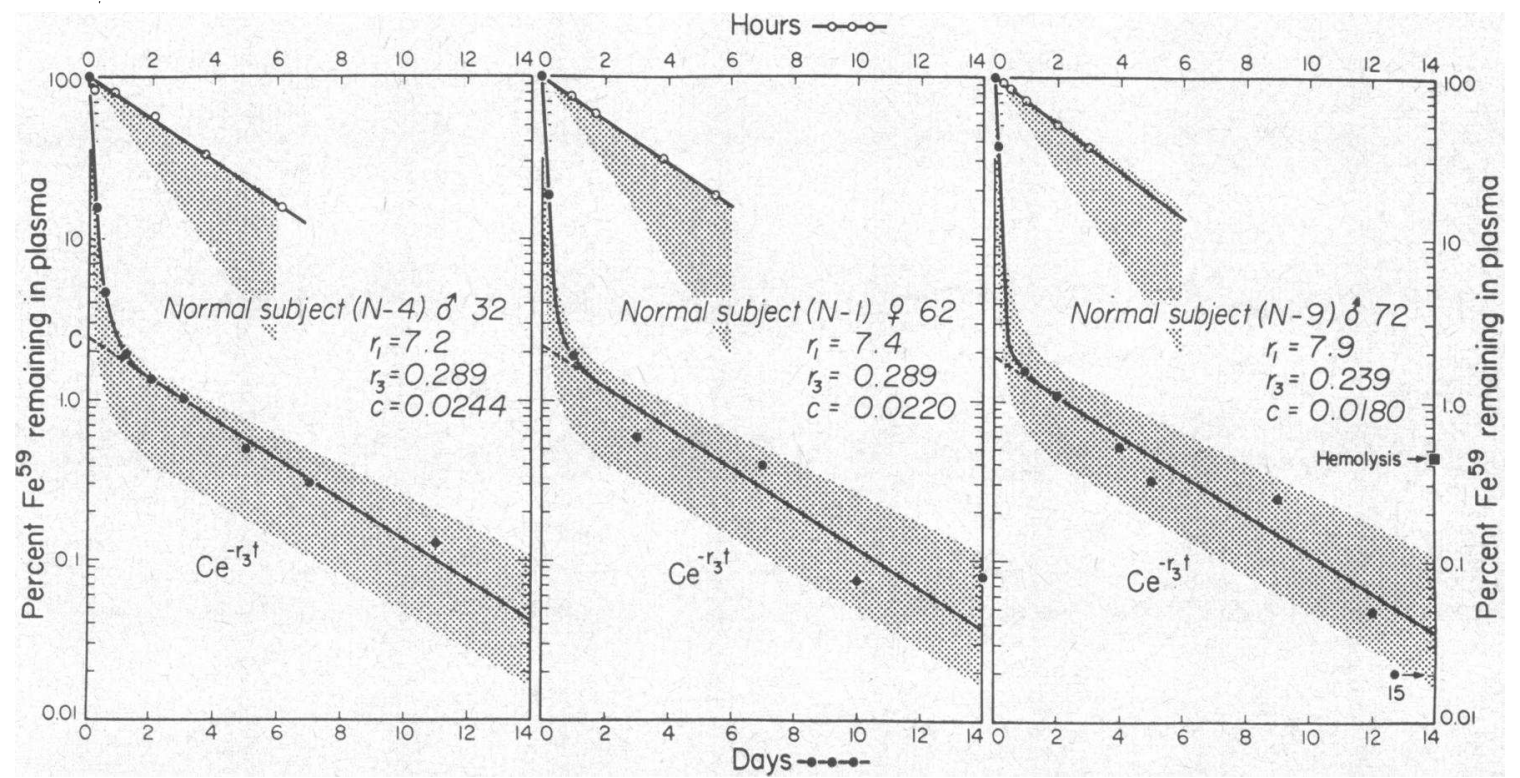

Fig. 14. Per Cent of Radioiron in plasma after intravenous injection. Plasma radioiron data in 3 representative normal subjects are shown. 
QUANTITATION OF IRON KINETICS AND HEMOGLOBIN SYNTHESIS

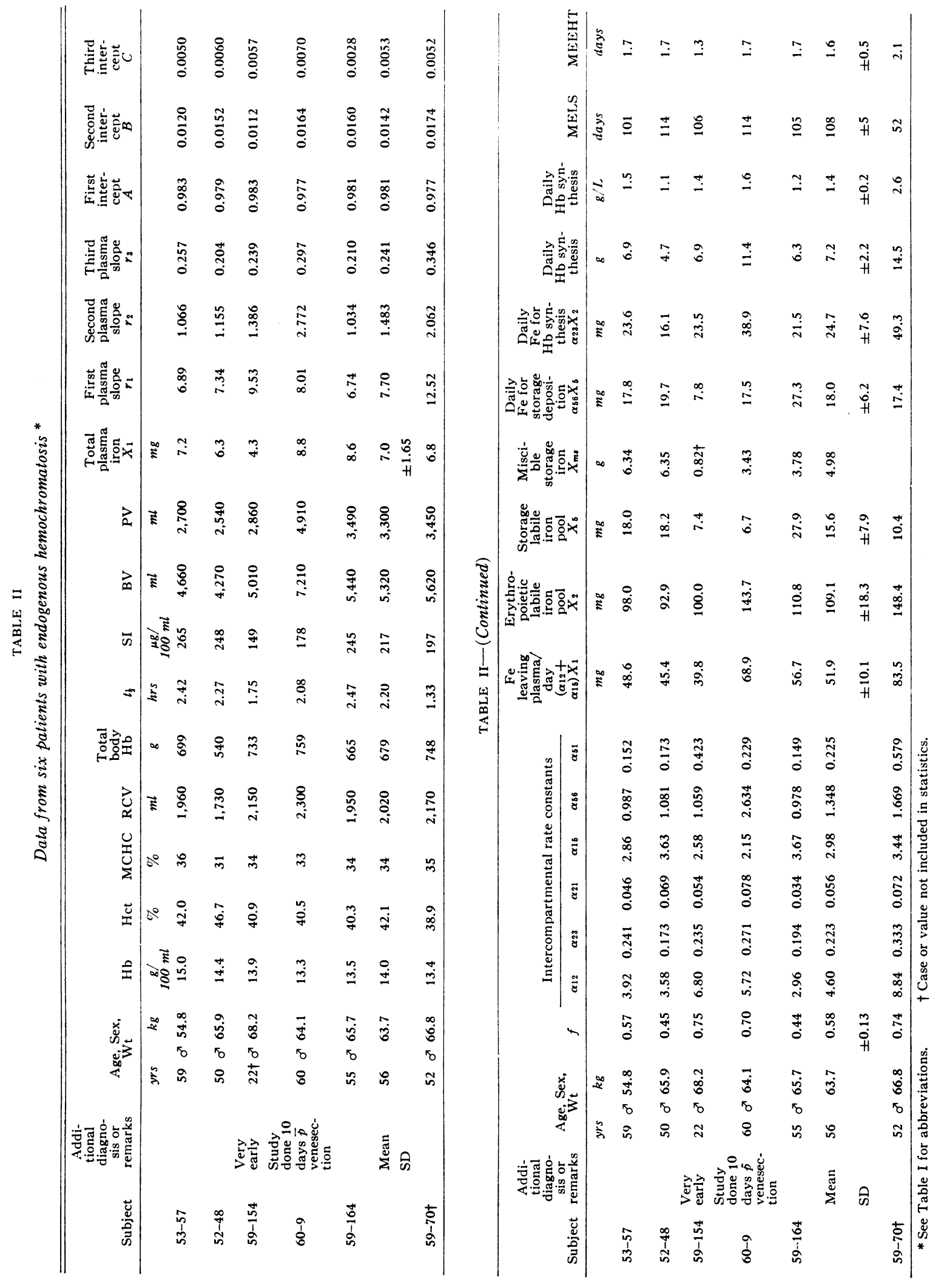


daily hemoglobin synthesis, mean erythrocyte life span, and MEEHT. The plasma radioiron curves in these patients may be resolved into three exponential components (Figures 6, 7, 10). Using the slopes and their intercepts, the following average estimates are obtained in patients with endogenous hemochromatosis : $51.9 \mathrm{mg}$ of iron leaves plasma daily $\left[\left(\alpha_{12}+\alpha_{15}\right) X_{1}\right]$, of which $24.7 \mathrm{mg}$ $\left(\alpha_{23} X_{2}\right)$, or 48 per cent, is used for hemoglobin synthesis, and $18.0 \mathrm{mg}$ per day $\left(\alpha_{50} X_{5}\right)$ goes into stores. The labile storage iron pool is $15.6 \mathrm{mg}$, approximately twice the plasma iron pool of 7.0 mg. Miscible storage iron in the four patients with advanced hemochromatosis without hemolysis averages $4,980 \mathrm{mg}$ as compared with $820 \mathrm{mg}$ in the young prehemochromatotic patient. Although only 58 per cent of the radioiron is incorporated into circulating erythrocytes, hemoglobin is synthesized at a normal rate of $7.2 \mathrm{~g}$ per day or $1.4 \mathrm{~g}$ per $\mathrm{L}$ per day. Corresponding mean erythrocyte life span is calculated to be 108 days. The estimated MEEHT is 1.6 days.

The compatibility of the predictions of the mathematical models with the experimental results was demonstrated by an analog computer. Intercompartmental rate constants were calculated from observed data using the formulae in Appendix $\mathrm{D}$ and inserted into the analog computer in both the "storage exchange" and "normal flow" models. The resultant radioiron curves obtained in plasma, labile erythropoietic, and labile storage compartments in the analog computer reproduce within 5 per cent the observed radioiron curves in plasma, sacral marrow, and liver.

\section{DISCUSSION}

Mathematical analysis of the proposed general model (Figure 11a) predicts that tracer radioiron within the plasma iron compartment should decrease with three exponential components when feedback from erythropoietic and storage pools is significant. More than two components are clearly present in the measured plasma radioiron of patients with hemochromatosis in whom significant exchange of iron between plasma and storage compartments is demonstrated by striking hepatic deposition of radioiron (Figures 6, 9, 10). When plasma iron transfer into the storage compartment is negligible, then the general model re- duces to the simpler one (Figure 5a) in which exponential decrease of plasma radioiron contains only two components. Measurements of plasma radioiron in normal subjects, in whom hepatic deposition of radioiron is small, demonstrate only two easily distinguishable exponential components, $x_{1}=A e^{-r_{1} t}+C e^{-r_{\mathrm{g}} t}$ (Figures 1, 2, 5, 14). $\mathrm{Pa}-$ tients with complete erythroid aplasia also demonstrate only two components of plasma radioiron; the slope of the second component, however, corresponds in magnitude to $r_{2}$, and $r_{3}$ is absent (21) ; plasma radioiron, $x_{1}=A e^{-r_{1} t}+B e^{-r_{2} t}$ (Figure 15). Using these models, the calculated rates of hemoglobin synthesis, when related to measured totalbody hemoglobin, result in estimates of erythrocyte life spans in normal subjects and patients with endogenous hemochromatosis within the previously established normal range of 100 to 130 days $(17,19)$. There was one exception, a patient (59-70) with endogenous hemochromatosis



Fig. 15. Per CENT of RAdioiron In Plasma after inTRAVENOUS INJECTION IN TWO PATIENTS WITH ERYTHROID APLASIA. The initial rapid exponential component is slower than normal while the second exponential storage deposition component is more rapid than the normal erythropoietic fixation component. 
whose plasma radioiron remained constant after Day 9 of the study (Figure 12). This corresponds to the "hemolytic" plasma radioiron pattern of Figure 11. The mean erythron life span of this patient with the "hemolytic" pattern, derived from rate of hemoglobin synthesis and measurements of circulating hemoglobin, was reduced to 52 days. All of the other 18 subjects (13 normal, 5 endogenous hemochromatosis) showed continued decrease of plasma radioiron at Day 10 (Figures 2, 7).

Patient $60-9$, with endogenous hemochromatosis, was venesected 10 days before the study began. Hemoglobin synthesis in this patient was increased to $11.4 \mathrm{~g}$ per day, or $1.6 \mathrm{~g}$ per $\mathrm{L}$ per day, as compared with $1.3 \pm 0.2 \mathrm{~g}$ per $\mathrm{L}$ per day in normal subjects and $1.4 \pm 0.2 \mathrm{~g}$ per $\mathrm{L}$ per day in the other hemochromatotic patients without hemolysis. Relating this increased rate of hemoglobin synthesis to total hemoglobin $(759 \mathrm{~g})$ and its increase during the study ( $4.8 \mathrm{~g}$ per day), a mean erythron life span of 114 days was obtained. This demonstrates increased production of erythrocytes with normal longevity in response to venesection.

Miscible storage iron in the four patients with advanced endogenous hemochromatosis without hemolysis averaged 4,980 mg. Hepatic ferritin, calculated from data obtained in three patients with endogenous hemochromatosis studied by Finch and Finch (23), averaged approximately 2,300 mg. Assuming that the liver contains almost half the total storage iron (30) and that ferritin is distributed in approximate proportion to hemosiderin, the value of $4,980 \mathrm{mg}$ obtained for miscible storage iron is not significantly in excess of estimated total ferritin in these patients. It thus appears that very little of the radioiron deposited in storage is fixed in hemosiderin during the 4 week period following injection of radioiron. Using a hepatic hemosiderin: ferritin ratio of 4.5 derived from the data of Shoden, Gabrio and Finch (35) and Finch and Finch (23) and equating ferritin to miscible storage iron, mean total storage iron of $27,400 \mathrm{mg}$ is calculated for the four patients of this study. Using a hepatic hemosiderin: ferritin ratio of 10.6 derived from the data of Heilmeyer in five patients with hemochromatosis (36), total storage iron of $57,700 \mathrm{mg}$ is calculated for these four patients. Miscible storage iron in the fifth patient, 22 years old and classified as prehemochromatotic, is only $820 \mathrm{mg}$. Assuming that this corresponds to ferritin, and using a smaller hemosiderin:ferritin ratio of 2.0 (35), calculated storage iron in this patient is only moderately increased to $2,460 \mathrm{mg}$; using the data of Heilmeyer, 4,670 mg. Miscible storage iron was not calculated in the sixth patient (59-70) with hemolysis, in whom a relatively high equilibrium level of plasma radioiron derived from erythron hemolysis is present $(\mathrm{D}+\mathrm{E}$, Figure 12). This is superimposed upon the lower equilibration level of storage pool radioiron with plasma ( $E$, Figure 10) so that storage equilibration could not be measured directly.

The mean erythron life span is calculated as the ratio of total hemoglobin to daily hemoglobin breakdown. assuming that measured erythrocyte kinetics is characteristic of the cells measured throughout their life span. Chromium ${ }^{51}$ and $\mathrm{DFP}^{32}$ (P32-diisopropyl fluorophosphate) label the population of circulating erythrocytes. If a population of erythrocytes with skewed distribution of potential life spans is released from the marrow, these cells do not have proportional representation in the circulation. At any given time the circulating blood will contain relatively fewer shortlived erythrons and, conversely, many more longlived erythrons than does the population originally released from the marrow. If destruction is not entirely random, numerical representation of circulating erythrons becomes weighted in proportion to longevity. On the other hand, the radioiron method presented measures mean erythron life span from the time of fixation of radioiron in maturing erythrons, beginning with the proerythroblast (37. 38). Mean erythron life span measured in this way is comparable with mean survival of the population of circulating erythrons, as determined with the Ashby, $\mathrm{DFP}^{32}$ or $\mathrm{Cr}^{51}$ techniques, only when erythron destruction is ranclom or occurs with a normal distribution about a definite time interval (21). When defective erythropoiesis results in marrow hemolysis of maturing erythrons or release into the circulation of a skew population, measurement of the circulating erythrons will result in survival times which are considerably longer than the mean erythron life span. A more detailed consideration of these problems together with observations in 
patients with hemolytic anemia will be presented elsewhere.

Analysis of earlier ferrokinetic models used for calculating red cell iron turnover and rate of hemoglobin synthesis $(1,2)$ suggests two reasons for the lack of agreement. The earlier proposal, that rate of iron fixation in erythrocytes is equal to the product of the rate of plasma iron removal and the fraction of radioactive iron found in circulating erythrocytes, implies a linear progression of radioiron from plasma to marrow to red cells without significant feedback. When the return of iron from labile erythropoietic and storage iron pools is neglected, an erroneously large rate of iron fixation in erythrocytes is estimated. In these normal subjects this error averages 52 per cent, while in the patients with endogenous hemochromatosis it averages 22 per cent. Another difficulty arises from equating the maximal fraction of radioiron present in circulating erythrocytes with the maximal fraction of radioiron fixed in maturing erythrons $(f)$. This difference becomes significant in active hemolytic states where maximal net incorporation of radioiron into circulating erythrocytes may be as little as 35 per cent (21), without appreciable initial hepatic deposition of radioiron. Under these circumstances, multiplication of plasma iron turnover by maximal net fraction of radioiron in circulating erythrocytes results in an erroneously small rate of iron fixation in erythrocytes. If, for example, in a patient with negligible plasma-storage iron exchange and severe hemolytic anemia $\left(\alpha_{23}+\alpha_{21}\right) / \alpha_{23}=6 / 5$ and maximal net incorporation of radioiron into circulating erythrocytes is one-third, then iron fixation in erythrons as calculated by multiplying plasma iron turnover by maximal net incorporation of radioiron into circulating erythrocytes would be only 40 per cent $(6 / 5 \times 1 / 3 \times 100$ per cent) of the actual iron fixation in erythrons.

In terms of the proposed mathematical models, initial accumulation of radioiron in sacral marrow is largely the result of transfer and equilibration of radioiron between the plasma and labile erythropoietic pools. If this marrow uptake, mirroring disappearance of radioiron from plasma and normally almost complete in 8 hours (Figures 1,4$)$, represented irreversible intracellular fixation of radioiron, then release of radioiron from marrow and its appearance in circulating erythrocytes would correspond to the division and maturation times of the various stages of erythron development in which iron is fixed. Since total division and maturation time of erythrons is estimated to be 2.5 to 3.0 days $(39,40)$, marrow release and appearance in circulating erythrocytes of radioiron would be complete in approximately 3 days. The observed time of 7 to 10 days required normally for maximal incorporation of radioiron into circulating erythrocytes (Figure 3 ) is consequently incompatible with the assumption that initial marrow accumulation of radioiron occurs by irreversible intracellular fixation in marrow erythrons. If, on the other hand, a nonerythropoietic labile pool (also a nonstorage labile pool, as shown by absence of considerable hepatic accumulation of radioiron) is postulated to supply radioiron to marrow via plasma at the appropriate rate, then sacral marrow radioiron accumulation would be much more gradual and reduced than that observed (Figure 4).

The concept of a labile erythropoietic pool is central to the proposed mathematical models. These models were first presented in $1956(5,6)$. At that time no morphologic or biochemical entity corresponding to such a pool had been observed. Bone marrow hemosiderin and ferritin were and still are considered part of the iron storage compartment. Subsequently in 1957, Bessis and Breton-Gorius, using electron microscopy, demonstrated that ferritin may be transferred by micropinocytosis from reticulum cells and extracellular fluid into the cytoplasm of maturing erythrons or, possibly, the reverse sequence occurs $(41-43)$. It is well established that ferritin is a labile form of iron in equilibrium with ionic iron: $\mathrm{Fe}^{+++}+$apoferritin $\rightleftarrows$ ferritin $(36,44-51)$. Since it is known that plasma iron is bound to transferrin $(52,53)$, the following over-all equilibrium is present : transferrin $-\mathrm{Fe} \rightleftarrows$ transferrin $+\mathrm{Fe}^{+++}+$ apoferritin $\rightleftarrows$ ferritin. It seems unlikely, however, that marrow ferritin constitutes the labile erythropoietic pool. Approximately half of the total storage iron is estimated to be present in marrow (30). In normal individuals ferritin and hemosiderin iron are approximately equal; usually slightly more ferritin than hemosiderin is present $(23,35)$. Marrow ferritin may thus normally represent one-half of total ferritin and one-quarter of total storage iron. Return of ra- 
dioiron from miscible storage iron to plasma is quite slow, becoming appreciable only after 14 days (Figure 7). Miscible storage iron is probably composed largely of ferritin, since it corresponds closely in magnitude to estimated total ferritin. Ferritin, then, appears to exchange with plasma relatively slowly, and hence does not exhibit the very high degree of lability of the labile erythropoietic pool. A more probable conjecture is that the labile erythropoietic pool consists of iron reversibly bound to the maturing erythron membrane, thereby being in a position to equilibrate rapidly with plasma, yet being simultaneously available for intracellular fixation in heme synthesis. Sondhaus and Thorell have recently shown by microspectrographic study of individual salamander erythrons that the ratio of nonheme iron (probably $\mathrm{Fe}^{+++}$) to hemoglobin iron exceeded 20 in the youngest cells and was approximately 2 from the time hemoglobin synthesis was one-third complete until maturity (54). Walsh and associates have suggested that the reticulocyte membrane functions as an intermediate link between plasma transport and heme synthesis (55). Jandl, Inman, Simmons and Allen have shown in man that iron bound to transferrin is actively transferred to the reticulocyte membrane, but not to mature erythrocytes (56). After incubation at $37^{\circ} \mathrm{C}$ for 2 hours of reticulocytes with $\mathrm{Fe}^{59}$-transferrin, approximately half of the reticulocyte $\mathrm{Fe}^{59}$ was associated with the reticulocyte membrane as nonheme iron, the other half was present in the cell interior, mostly as heme iron. The uptake of iron by reticulocytes was shown not to be primarily linked to heme synthesis. $\mathrm{Pb}^{++}\left(10^{-4} \mathrm{M}\right)$ blocked iron incorporation into heme without reducing iron transfer, with resultant accumulation of iron on the reticulocyte membranes.

The erythropoietic labile pool, as calculated in this study, is decreased or absent in anemias with erythroid hypoplasia or aplasia (21). This finding would be expected if the erythropoietic labile pool consists of iron bound to membranes of immature erythrons. This hypothesis is also supported by preliminary measurements in our laboratory of canine marrow and human and rabbit reticulocytes (21). In normal dogs, 8 hours after most of the tracer plasma radioiron had accumulated in marrow, approximately half of the marrow radioiron was present as erythron nonheme radioiron. The nonheme radioiron was associated chiefly with the erythron membrane, while most of the heme radioiron was present in the erythron interior. Heme radioiron was determined in human circulating erythrons by measuring the specific activity of doubly crystallized heme. These measurements were made at varying intervals during an iron kinetic study. The percentage of erythron radioiron present in heme was found to be 43 per cent at Day 1, 56 per cent at Day 2 and 98 per cent at Day 14. These values are in close agreement with the independently calculated rate constant for transfer from the labile pool to fixed iron in erythrons, $\alpha_{23}=0.49$. In an untreated patient with iron deficiency and polycythemia vera this transfer was greatly accelerated, with 78 per cent at 2.7 hours and 94 per cent at 1 day of erythron radioiron present in heme; these values are in agreement with the independently calculated $\alpha_{23}=17$. Human and rabbit reticulocytes were labeled in vivo by transfer of tracer radioiron from plasma transferrin. Incubation of the washed, labeled reticulocytes in plasma for 1 hour resulted in transfer of up to 17 per cent of the reticulocyte radioiron back to plasma (but not to acid citrate dextrose solution), thereby demonstrating the lability of iron in immature erythrons.

The application of this model in normal subjects provides estimates of hemoglobin synthesis which correspond to well accepted values for normal life span of circulating erythrocytes (17-20). Since iron absorption is roughly equivalent to daily iron loss of $1.2 \mathrm{mg}$ per day (57-67), net iron removed from plasma for hemoglobin synthesis, $21.4 \mathrm{mg}$ per day, under steady state conditions [Table I: $\alpha_{12} X_{1}$ (32.5 mg per day) $-\alpha_{21} X_{2}$ (11.1 mg per day)] must enter plasma directly or indirectly from destroyed red cells. It follows that-unless the life span of normal circulating erythrocytes is significantly shorter than the finite life span well established by previous studies of Ashby, Eadie and Brown, and Pollycove and coworkers (17-20), thereby releasing more than 21 $\mathrm{mg}$ iron per day for fixation in maturing erythrons-only insignificant amounts of iron from circulating erythrocytes could bypass plasma (via breakdown of circulating erythrocytes to ferritin within marrow reticulum cells and subsequent 


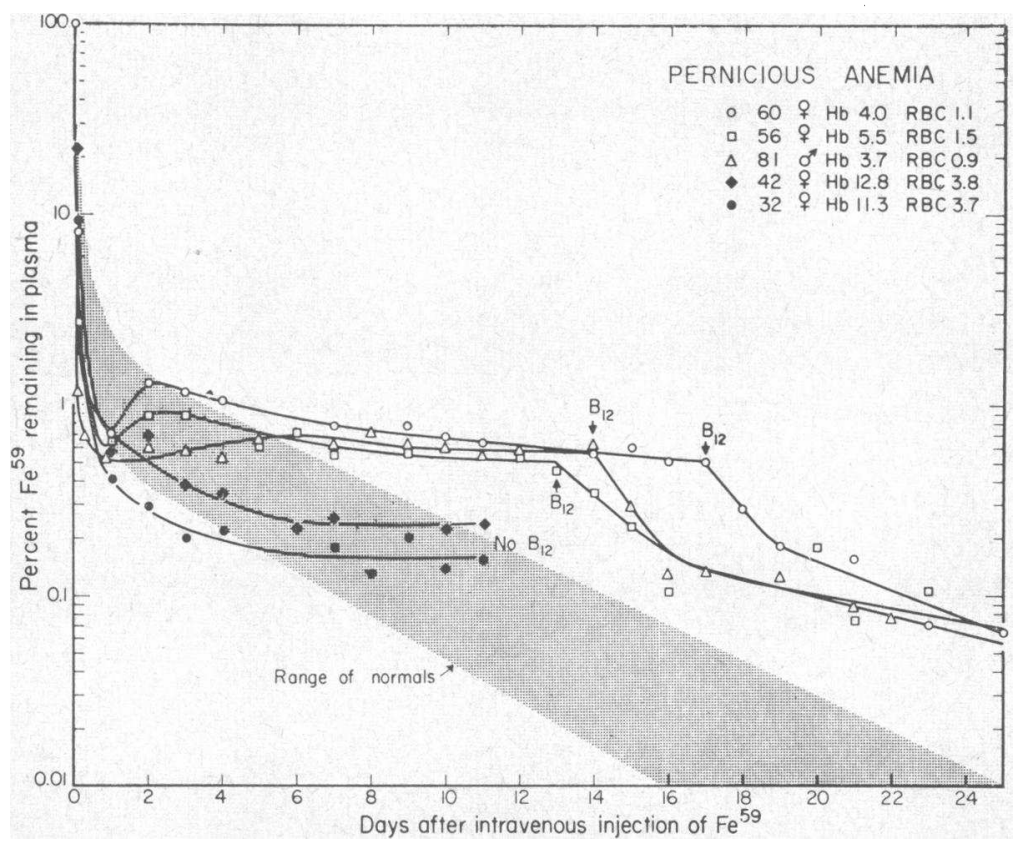

Fig. 16. Per Cent of Radioiron in Plasma after intravenous injecTION IN PATIENTS WITH PERnicious ANEMIA. Plasma radioiron of patients with severe anemia in relapse reaches a minimal value within 1 day and subsequently increases. Administration of vitamin $B_{12}$ is followed by rapid and sustained decrease of $\mathrm{Fe}^{38}$. Plasma radioiron of patients with borderline anemia equilibrates at a constant level within 6 days.

direct transfer of this ferritin from cytoplasm of reticulum cells into cytoplasm of immature erythrons) (43). It is conceivable, however, that iron from normal destruction in the marrow of a small fraction of maturing erythrons is complexed to ferritin in marrow reticulum cells, and then reincorporated into other erythrons, without entering plasma or labile erythropoietic compartments. This breakdown of hemoglobin during erythron maturation was first suggested by the findings of London, West, Shemin and Rittenberg (68) and Gray, Neuberger and Sneath (69) to explain the early presence in normal subjects of a relatively high specific activity of $\mathrm{N}^{15}$-stercobilin at a time when specific activity of circulating $\mathrm{N}^{15}$ hemin is low ; 11 to 20 per cent of total $\mathrm{N}^{15}$-stercobilin being recovered in the initial 8 day period following ingestion of $\mathrm{N}^{15}$-glycine. Other explanations of this finding suggested by these workers are that the stercobilin may be derived from porphyrins not synthesized into hemoglobin or from bile pigment not derived from degradation of a porphyrin ring. When erythron hemolysis occurs in marrow, erythroblastic (or megaloblas- tic) karyorrhexis and erythrophagocytosis (7072) and characteristic uniformity of hemosiderin granulation (73) are seen. The erythrophagocytosis results from the death of erythrons. It is doubtful that viable erythrons are phagocytized (71). This occurs in pernicious anemia, erythremic myelosis, refractory anemia with erythroid hyperplasia, and thalassemia major $(73,74)$. The mean effective erythron hemoglobinization time in these disorders is prolonged markedly (Figure 13), and plasma radioiron stabilizes in 2 days or less at a high equilibrium level (Figures $5 \mathrm{~b}, \mathrm{D} ; 16)$; parenteral administration of vitamin $\mathrm{B}_{12}$ to patients with pernicious anemia in relapse results in a prompt exponential decrease of plasma radioiron (Figure 16). These observations suggest that there is relatively little shunting of plasma by iron via the pathway: reticulum cell erythrophagocytosis $\rightarrow$ reticulum cell ferritin $\rightarrow$ micropinocytosis $\rightarrow$ erythron ferritin. Two female patients with clinically mild pernicious anemia were studied. The hemoglobin concentrations were 12.8 and $11.3 \mathrm{~g}$ per $100 \mathrm{ml}$; the hematocrits, 39 and 37 per cent, and red blood cells 3.8 and 3.7 million 
per $\mathrm{mm}^{3}$. Plasma radioiron in both cases stabilized at a constant equilibrium level in 6 days (Figure $16)$, in contrast to the exponential decrease of radioiron for approximately 14 days in all 13 normal subjects (Figures 1,2,14). These observations suggest that in normal subjects there is no significant destruction of maturing erythrons with direct reincorporation of all recovered iron, thereby bypassing plasma and labile erythropoietic iron compartments.

There remains the possibility that iron irreversibly fixed in marrow erythrons constitutes the labile erythropoietic pool. If this obtained, then approximately one-third of all iron fixed in erythrons would normally be quickly returned to plasma as a result of destruction of maturing erythrons and only one-quarter of the total number per day $\left(\alpha_{23}=0.258\right.$, Table I $)$ would survive to mature and enter the circulation without destruction. This degree of destruction is not compatible with the $\mathrm{N}^{15}$-stercobilin measurements of London (68) and Gray (69) and their colleagues nor with morphologic examinations of normal marrow (70-73). Iron is chelated very tightly to transferrin so that no significant dissociation occurs $(52,53)$. This precludes the possibility that significant amounts of dissociated $\mathrm{Fe}^{59}$ escape through the capillary walls and become bound to extravascular protein. One must consider the possibility that a considerable fraction of $\mathrm{Fe}^{59}$-transferrin transfers into the extravascular fluid and that re-entry of radioiron into plasma occurs from this extravascular pool. Transferrin exchange with extravascular extracellular fluid, however, is relatively slow, the halftime being approximately 30 hours $(75,76)$. This is quite long compared with 2.5 hours, the longest half-time of initial plasma radioiron decrease observed in patients with hemochromatosis. Less than 10 per cent of the radioiron transfers to extracellular fluid in this patient and approximately only 5 per cent in normal subjects. This is insufficient to explain the prolonged appearance of radioiron in circulating erythrocytes if all erythron radioiron were irreversibly fixed.

Measurements of surface radioactivity in normal subjects show that as radioiron is removed from plasma, hepatic radioactivity usually decreases or, at most, remains constant (Figures 1, 4). Uptake of radioiron in rib marrow and, to a slight extent, vertebral marrow also contributes to the "hepatic" counting rate. This means that, normally, maximal deposition of radioiron in liver is less than radioiron initially present in hepatic plasma. Since liver contains approximately half of the body iron stores (30), and on the assumption that blood comprises approximately 18 per cent of liver $(1,500 \mathrm{~g})(77,78)$, we estimate that maximal iron deposition in stores is less than 10 per cent of total fixation of plasma iron in normal subjects. Measurements of net incorporation of radioiron into erythrocytes are in close agreement with this estimate (Figures 1, 3). The av-

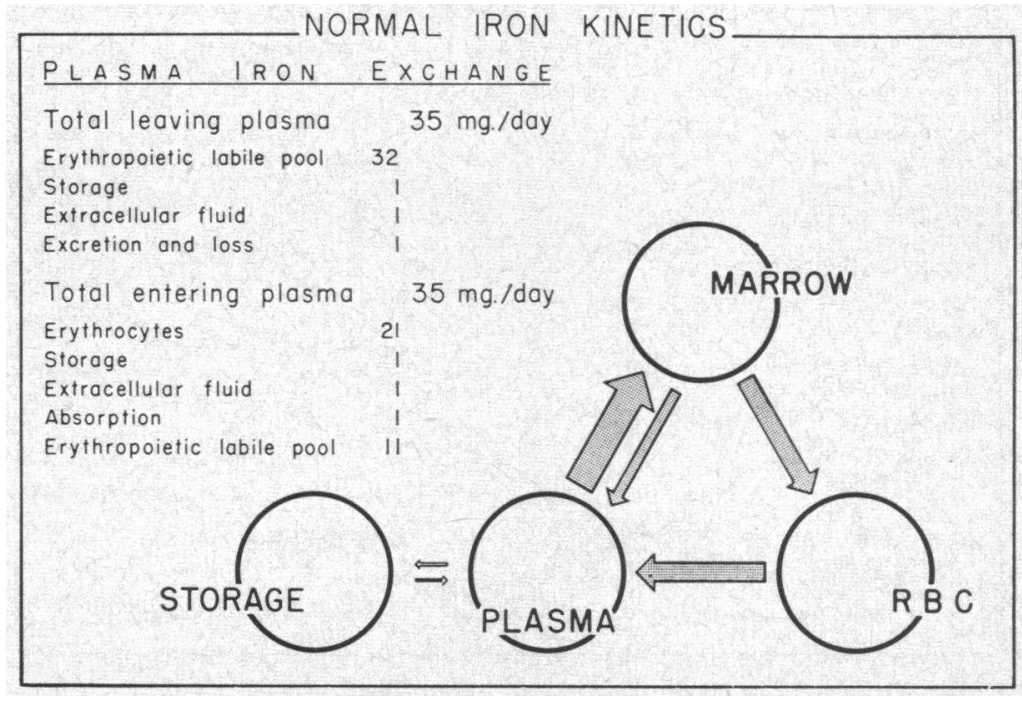

Fig. 17. QUANTitative ASPECtS OF NORMal IRON Kinetics. 


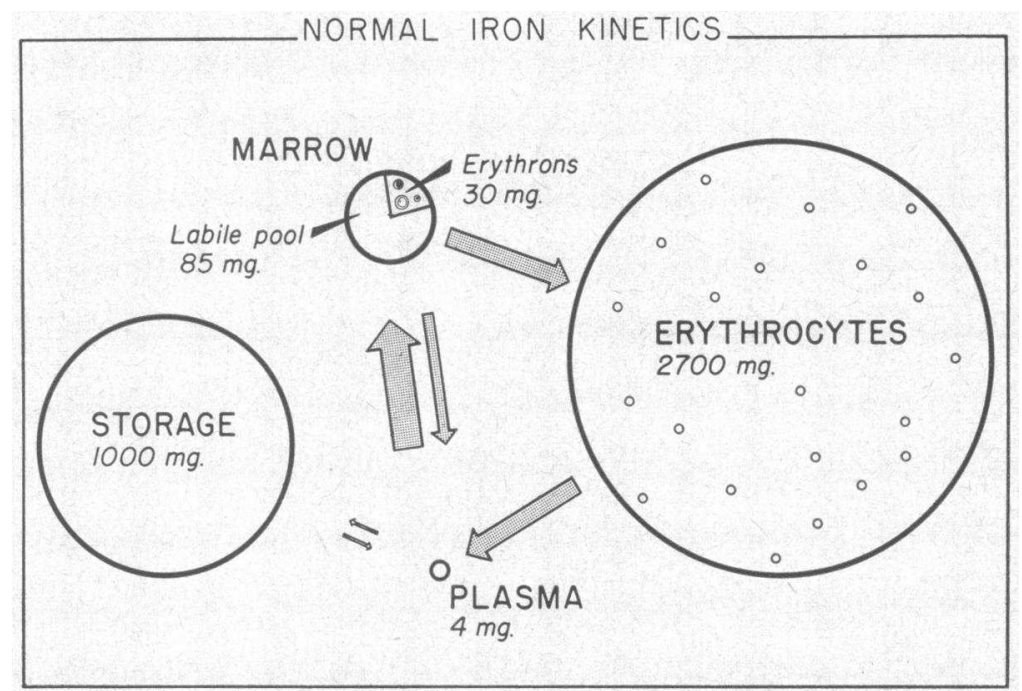

Fig. 18. NORMal Distribution OF IRON In various COMPARTMENTS.

erage daily fixation of iron in maturing erythrons is $21.4 \mathrm{mg}$ per day in normal subjects; storage iron deposition is estimated to be less than onetenth this amount, or between 0 and $2 \mathrm{mg}$ per day. Relating MEEHT of 1.4 days to daily fixation of iron in maturing erythrons, $21.4 \mathrm{mg}$ per day, results in a total amount of $1.4 \times 21.4=30.0 \mathrm{mg}$ of iron irreversibly fixed in maturing erythrons. From these considerations, the observations and results presented in Tables $I$ and II, and established data concerning body iron stores (47), iron absorption (58-67), iron excretion $(57,60)$, and plasma globulin exchange with extracellular fluid $(75,76)$, the main pathways and compartments may be represented as in Figures 17 and 18. Corresponding pathways and compartments in patients with endogenous hemochromatosis without hemolysis are illustrated in Figures 19 and 20.

Mean effective erythron hemoglobinization time is the mean time interval between fixation of radioiron in maturing erythrons and appearance of radioiron in circulating erythrocytes. This is shown in Figures 1, 6, and 13 and calculated in Appendix C. Radioiron enters and is fixed in

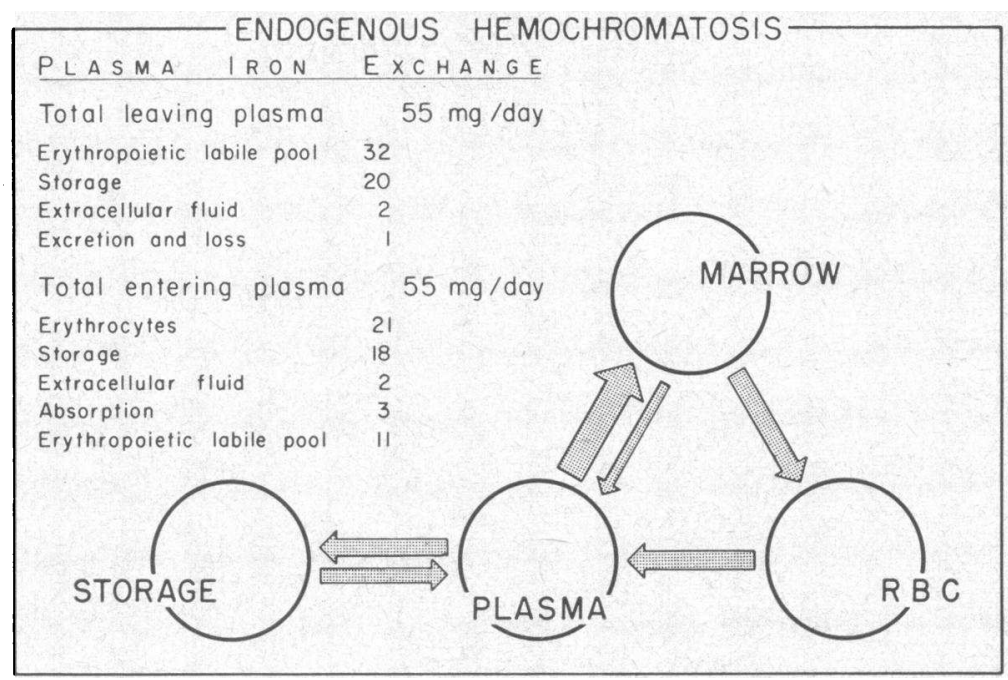

Fig. 19. Quantitative ASPECtS OF IRON Kinetics In PATIENTS With ENDOGENOUS HEMOCHROMATOSIS. 


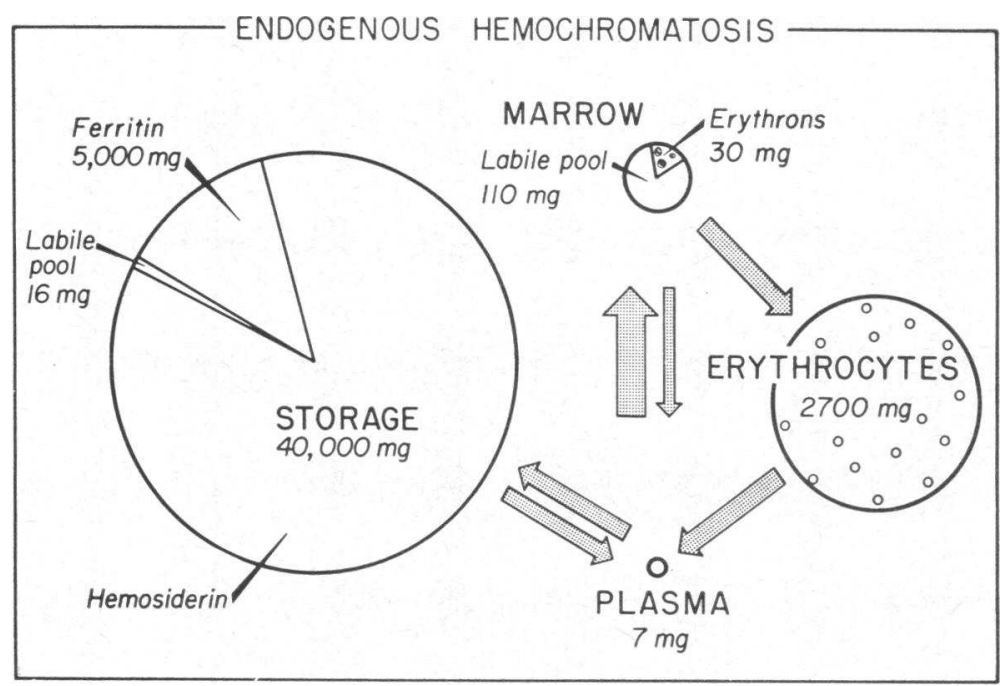

Fig. 20. Distribution OF IRON IN VARIOUS COMPARTMENTS IN PATIENTS WITH ENDOGENOUS HEMOCHROMATOSIS.

maturing erythrons at all stages of development. The amount of radioiron per cell is high for young cells and low for older ones $(37,38)$. However, many more erythrons at the later stages of development are present. Consequently, the mean time intervals from fixation to appearance in circulating erythrocytes (mature erythrons) is probably comparable in magnitude with a mean hemoglobinization time averaged over all stages of development. Total division and maturation time for erythrons, 2.5 to 3.0 days, has been estimated from mitotic counts and ratios of cell counts of erythrons of varying maturity $(37,38)$. Since radioiron enters maturing erythrons at all stages of development, the MEEHT may be expected to be roughly of the order of one-half total erythron division and maturation time. MEEHT of $1.4 \pm$ 0.4 days in normal subjects and 1.6 days in patients with endogenous hemochromatosis were calculated. These are approximately one-half the total erythron division and maturation time.

The delay of radioiron incorporation into circulating erythrocytes which is seen in patients with hemochromatosis probably is not the result of hemolysis of maturing erythrons, delayed erythron maturation, or increased intermitotic interval, since MEEHT is normal. The most probable cause of the delay is the increased time required for removal of radioiron from the increased labile iron pool (Figure 13, Appendix C). Conversely, when erythropoiesis is greatly increased, abnor- mally rapid incorporation of radioiron into circulating erythrocytes probably is not the result of shortened erythron maturation, decreased intermitotic interval, or a decrease in normal destruction of maturing erythrons as suggested by Stohlman (79), since MEEHT is normal (Figure 13, sickle cell anemia) (21). Early delivery into the circulation of a large fraction of reticulocytes and a few nucleated erythrons could conceivably shorten total division and maturation time in the marrow by as much as a full day. Since radioiron is fixed in maturing erythrons at all stages of development, the mean time for radioiron to appear in circulating erythrocytes could be shortened in this way by only one-half or, at the very most, three-quarters of a day. Early release of maturing erythrons cannot be the major factor in reduction of mean time required for appearance of circulating radioiron from 4 days in normal subjects to 2 days in patients with greatly increased erythropoiesis (Figure 13, sickle cell anemia). Rapid incorporation of radioiron into circulating erythrocytes is probably largely the result of rapid fixation of radioiron in maturing erythrons-i.e., $\alpha_{23}$ is increased, in accordance with the proposed mathematical model (Figure 13, sickle cell anemia, Appendix C). When this occurs, and the mean effective erythron hemoglobinization time is normal-i.e., marrow hemolysis is absent-labeling of erythrons may be complete in a fraction of a day, and the time interval between the maximal 
net incorporation of radioiron into erythrons and maximal net incorporation into circulating erythrocytes furnishes a good estimate of the time required for the earliest labeled cell, the proerythroblast (37), to divide, mature, and enter the blood. This time interval is approximately 3 days, as shown in Figure 13, sickle cell anemia, and is not appreciably shortened even in the most severe hemolytic anemias $(21,22)$. These observations are compatible with the concept that compensatory increased erythropoiesis is the result of increased division of erythroid precursors more immature than proerythroblasts, or increased differentiation of multipotential stem cells into erythroid precursors which then proceed to divide and mature in normal fashion, as proposed by Osgood (80), Alpen and Cranmore (81) and Erslev (82).

Markedly increased amounts of $\mathrm{N}^{15}$-stercobilin in the first week after ingestion of $\mathrm{N}^{15}$-glycine (83) and markedly increased marrow erythrophagocytosis (70-72) have been observed in patients with pernicious anemia. These observations indicate that marrow hemolysis of maturing erythrons, not prolonged erythron maturation or increased intermitotic interval, is responsible for the marked increase of mean effective erythron hemoglobinization time (Figure 13). The term, mean effective erythron hemoglobinization time, is used because, when hemolysis occurs in marrow, the time interval between initial fixation of some radioiron in maturing erythrons and the appearance of this label in a cell that reaches the circulation may span two or more passages through the marrow maturational pathway $(21,22,34,70$, $73,84)$.

The calculated amounts of miscible storage iron in the patients with endogenous hemochromatosis correspond closely with estimates of total ferritin derived from direct measurements of hepatic ferritin $(23,35)$. The amount of iron calculated to be present normally in the labile erythropoietic pool (84 mg) lies well within the accepted normal range of 750 to $1,500 \mathrm{mg}$ of total-body nonhemoglobin iron (47). The labile erythropoietic pool was found to be increased to a mean of 117 $\mathrm{mg}$ in the 6 patients with endogenous hemochromatosis and reduced markedly in 11 patients with iron-deficiency anemia to a mean of $14 \mathrm{mg}(8,21$, 22). In these iron-deficient patients the mean fraction of labile pool turnover fed back to plasma, $\alpha_{21} /\left(\alpha_{23}+\alpha_{21}\right)$, is $0.066(8,21,22)$, compared with a normal mean of 0.342 . This suggests that the fraction of the total amount leaving the labile pool that is not utilized for hemoglobin synthesis is greatly decreased when the pool size is very small. The distribution and movement of iron, as calculated from mathematical application of the proposed model, appears consistent with established data concerning erythrocyte life span, totalbody nonhemoglobin iron, erythron division and maturation time, and concepts regarding mass action equilibria.

\section{CONCLUSIONS AND SUMMARY}

A mathematical model of iron kinetics is proposed and used in the study of 13 normal subjects and 6 patients with endogenous hemochromatosis. Of central importance to this model is the concept of a labile erythropoietic iron pool interposed between iron bound to transferrin in plasma and iron irreversibly fixed in erythrons for heme synthesis. This model is applied to measurements of radioiron in plasma, circulating red cells, and surface counting rates over liver, spleen, and marrow. Together with measurements of plasma iron concentration and red cell volume, this permits calculation of hemoglobin synthesis, mean erythron life span, mean effective erythron hemoglobinization time, storage iron deposition, and miscible storage iron. Results are presented that are in agreement with established concepts concerning the life span of normal erythrocytes, erythron maturation, and body iron stores. Increased storage iron deposition, miscible storage iron, and plasma iron removal were evident in all hemochromatotic patients. Hemoglobin synthesis and erythron life span were normal in five patients with hemochromatosis; one was found to have compensated hemolysis. Erythron hemolysis, whether in marrow, or subsequent to erythron entry into the circulation, may be detected and quantitated by analysis of plasma radioiron, which, as a result of hemolysis, equilibrates at a constant value in 10 days or less. Evidence is presented suggesting that there is insignificant erythron iron bypass of plasma, either by destruction of maturing erythrons in the marrow or via erythrophagocytosis in marrow of circulating erythrocytes. 


\section{APPENDIX A}

In this section a mathematical analysis of the kinetics model illustrated in Figure 11a is presented; the slow return to plasma of iron from storage reserve shown in Figure 11b is neglected. The objectives of this analysis are to obtain a qualitative picture of the turnover of iron and to derive equations, based on the turnover of labeled iron in the various compartments, which can be applied to experimental data in order to determine the rate constants describing the ferrokinetic system.

The conditions assumed in this analysis are:

1) The exchange of iron (labeled or unlabeled) between the various compartments obeys first order kinetics. Delay is assumed to be absent, an assumption known to be incorrect for compartment 3 , representing the erythropoietic series. If feedback from this compartment or from the mature red cells (compartment 4 ) does not occur during the course of the experiment, this will not affect predictions for the turnover of labeled iron in the plasma (or other compartments). An empirical method for estimating the delay in the erythropoietic series is presented in Appendix $\mathrm{C}$.

2) Let $X_{i}$ be the amount of iron (labeled and unlabeled) in compartment $i$, and $x_{i}$ the amount of labeled iron in this compartment. Let $\alpha_{i j}$ represent the rate constant from compartments $i$ to $j$. It is assumed the $\alpha_{i j}$ 's have the same value for labeled and unlabeled iron. Further, the $\alpha_{i j}$ 's are assumed to remain constant.

With the above assumptions, the amount of labeled iron leaving compartment $i$ for compartment $j$ per unit time is $\alpha_{i j} x_{i}$. The equations describing the turnover of radioactive iron in the general model illustrated in Figure 11a follow.

$$
\begin{aligned}
& d x_{1} / d t=-\left(\alpha_{12}+\alpha_{15}\right) x_{1} \quad+\alpha_{21} x_{2} \quad+\alpha_{51} x_{5} \\
& d x_{2} / d t= \\
& \alpha_{12} x_{1}-\left(\alpha_{21}+\alpha_{23}\right) x_{2} \\
& d x_{3} / d t= \\
& \alpha_{23} x_{2}-\alpha_{34} x_{3} \\
& d x_{4} / d t= \\
& d x_{5} / d t= \\
& \alpha_{15} x_{1} \\
& \alpha_{34} x_{3} \\
& d x_{6} / d t= \\
& -\left(\alpha_{51}+\alpha_{56}\right) x_{5} \\
& \alpha_{56} x_{5}
\end{aligned}
$$

The boundary conditions representing injection of labeled iron into the plasma at $t=0$ are: $x_{1}(0)=1 ; x_{2}(0)=x_{3}(0)$ $=x_{4}(0)=x_{5}(0)=x_{6}(0)=0$.

Equations 1 may be solved by using the Laplace transform. With the above boundary conditions, the general solution for compartment 1 is:

$$
x_{1}(t)=A e^{-r_{1} t}+B e^{-r_{2} t}+C e^{-r_{3} t} .
$$

For the cases in which significant storage of iron occurs the plasma clearance curve can be resolved into three exponential components in agreement with the above equation. The values of $A, B, C, r_{1}, r_{2}$ and $r_{3}$ are described by the following equations.

$$
\begin{aligned}
a+b & =A\left(r_{2}+r_{3}\right)+B\left(r_{1}+r_{3}\right)+C\left(r_{1}+r_{2}\right) \\
a b & =A r_{2} r_{3}+B r_{1} r_{3}+C r_{1} r_{2} \\
c & =r_{1}+r_{2}+r_{3} \\
d & =r_{1} r_{2}+r_{1} r_{3}+r_{2} r_{3} \\
e & =r_{1} r_{2} r_{3}
\end{aligned}
$$

where

$$
\begin{aligned}
a & =\alpha_{51}+\alpha_{56} \\
b & =\alpha_{21}+\alpha_{23} \\
c & =\alpha_{12}+\alpha_{15}+\alpha_{21}+\alpha_{23}+\alpha_{51}+\alpha_{56}=\alpha_{12}+\alpha_{15}+a+b \\
d & =\alpha_{12}\left(\alpha_{23}+a\right)+\alpha_{15}\left(\alpha_{56}+b\right)+a b \\
e & =\alpha_{1: \alpha_{23}} a+\alpha_{15} \alpha_{56} b .
\end{aligned}
$$

The values $a, b, c, d$, and $e$ can be determined from the experimental plasma iron curve, using Equations 3. These values can then be introduced into Equation 4 to solve for the $\alpha$ 's. However, there are six unknowns and only five equations. An additional equation dependent upon the $\alpha$ 's describes the fraction $f$ of labeled iron that appears in red cells at the end of the initial phase of incorporation--i.e., at approximately 2 weeks, when red cell incorporation of radioiron from storage reserve is still negligible.

$$
f=\frac{\left(\alpha_{23} / b\right) \alpha_{12}}{\left(\alpha_{23} / b\right) \alpha_{12}+\left(\alpha_{56} / a\right) \alpha_{15}} .
$$

Solution of Equations 4 and 5 yields values for the different $\alpha$ 's. The method of data reduction is described in Appendix D.

The model for normal iron kinetics illustrated in Figure 5 is a special case of this more general model. The amount of iron going to stores is very small. In this case $\alpha_{15} \simeq 0$. The predicted plasma iron curve reduces to a sum of two exponentials.

$$
x_{1}(t)=A e^{-r_{1} t}+C e^{-r_{3} t} .
$$

The values of $A, C, r_{1}$ and $r_{3}$ are related to the rate constants by the following equations.

$$
\begin{aligned}
A r_{3}+C r_{1} & =\alpha_{21}+\alpha_{23} \\
r_{1}+r_{3} & =\alpha_{12}+\alpha_{21}+\alpha_{23} \\
r_{1} r_{3} & =\alpha_{12} \alpha_{23} .
\end{aligned}
$$

The method of solution of Equations 7 to determine values for the rate constants is described in Appendix D.

\section{APPENDIX B}

Calculation of hemoglobin synthesis, iron deposition and mean erythron life span

1. Hemoglobin synthesis. Iron irreversibly fixed each day in maturing erythrons for hemoglobin synthesis is equal to the product of the amount of iron in the labile erythropoietic pool $\left(X_{2}\right)$ and the fraction of this pool irreversibly fixed each day in maturing erythrons $\left(\alpha_{23}\right)$. Fe for $\mathrm{Hb}$ synthesis (RBC Fe turnover) $=\alpha_{23} X_{2} \mathrm{mg} /$ day.

$$
\begin{aligned}
& X_{2}= \alpha_{12} X_{1} / b \quad\left[\text { since } \alpha_{12} X_{1}=\left(\alpha_{23}+\alpha_{21}\right) X_{2} ;\right. \\
& X_{1}\left.=\text { amount of iron in plasma } b=\alpha_{23}+\alpha_{21}\right] \\
&=[\text { plasma Fe conc. }(\mu \mathrm{g} / \mathrm{ml}) \times \text { plasma vol }(\mathrm{ml}) / \\
&1,000(\mu \mathrm{g} / \mathrm{mg})] \mathrm{mg} .
\end{aligned}
$$

Assuming negligible nonhemoglobin iron in mature erythrocytes and since $1 \mathrm{~g}$ hemoglobin contains $3.4 \mathrm{mg}$ iron,

$$
\text { daily hemoglobin synthesis }=\left(\alpha_{23} X_{2} / 3.4\right) \mathrm{g} \text {. }
$$


2. Iron deposition. Iron deposition in relatively fixed stores is equal to the product of the amount of iron in the labile storage pool $\left(X_{5}\right)$ and the fraction of this pool deposited each day in relatively fixed storage form $\left(\alpha_{56}\right)$. Iron deposition $=\alpha_{56} X_{5} \mathrm{mg} /$ day.

$$
\begin{aligned}
X_{5}=\alpha_{15} X_{1} / a \quad\left[\text { since } \alpha_{15} X_{1}\right. & =\left(\alpha_{56}+\alpha_{51}\right) X_{5} ; \\
\text { and } a & \left.=\alpha_{56}+\alpha_{51}\right] .
\end{aligned}
$$

3. Miscible storage iron. The constant fraction of radioiron in plasma gradually reached after 2 weeks, $E$, may be viewed as the result of mixing a fraction of radioiron, $1-f$, initially in plasma iron, $X_{1}$, with a miscible storage pool of iron, $X_{m s}$.

$$
\begin{aligned}
1-f & =\frac{E}{X_{1}}\left(X_{1}+X_{m s}\right) \\
X_{m s} & =\frac{(1-f) X_{1}}{E}-X_{1}=\frac{(1-f-E) X_{1}}{E} \mathrm{mg} \\
& =\frac{(1-f) X_{1}}{E} \mathrm{mg} \quad(\text { since } 1-f \gg E) .
\end{aligned}
$$

4. Mean erythron life span. Mean erythron life span $=[$ total hemoglobin $(\mathrm{g}) /$ daily hemoglobin loss $(\mathrm{g} /$ day $)]$ days:

a) When total hemoglobin remains constant-i.e., red cell volume remains constant during the period of studydaily $\mathrm{Hb}$ loss = daily $\mathrm{Hb}$ synthesis;

b) When total hemoglobin is decreasing-i.e., initial red cell volume is greater than final red cell volume-daily $\mathrm{Hb}$ loss = daily $\mathrm{Hb}$ synthesis + daily total $\mathrm{Hb}$ decrement $\left(\Delta \mathrm{Hb}_{d}\right)$;

c) When total hemoglobin is increasing-i.e., initial red cell volume is less than final red cell volume-daily $\mathrm{Hb}$ loss = daily $\mathrm{Hb}$ synthesis - daily total $\mathrm{Hb}$ increment $\left(\Delta \mathrm{Hb}_{i}\right)$. So that for all cases $(\mathrm{a}, \mathrm{b}, \mathrm{c})$ :

Mean erythron life span

$$
=\frac{\text { total hemoglobin }(\mathrm{g})}{\text { daily hemoglobin synthesis }+\mathrm{Hb}_{d}(\mathrm{~g} / \text { day })} \text { day }
$$

where

$$
\begin{aligned}
\mathrm{Hb}_{d} & =\frac{\left(\mathrm{RCV}_{0}-\mathrm{RCV}_{f}\right) \mathrm{MCHC} / 100}{t} \mathrm{~g} / \mathrm{day} \\
\mathrm{Hb}_{i} & =\frac{\left(\mathrm{RCV}_{f}-\mathrm{RCV}_{0}\right) \mathrm{MCHC} / 100}{t} \mathrm{~g} / \mathrm{day}
\end{aligned}
$$

$\mathrm{RCV}_{0}=$ initial red cell volume $(\mathrm{ml}) ; \mathrm{RCV}_{f}=$ final red cell volume $(\mathrm{ml}) ; \mathrm{MCHC}=$ mean corpuscular hemoglobin concentration (per cent) $t=$ days between initial and final red cell volume measurements.

\section{APPENDIX C}

\section{Calculation of mean effective erythron hemoglobinization time}

The time interval between incorporation of iron into marrow erythrons and its appearance in circulating erythro- cytes is designated as the mean effective erythron hemoglobinization time (MEEHT). Cumulative incorporation of radioiron into maturing erythrons is calculated from the intercompartmental rate constant $\alpha_{23}$ and the maximal net incorporation of radioiron into erythrocytes, $N_{\max }$. $N_{\max }$, the net fraction of radioiron involved in erythropoiesis is equal to the total fraction involved in erythropoiesis, $f$, only when hemolysis is absent. $N_{\max }$ is partitioned between a) the combined plasma and labile erythropoietic compartments, and b) the maturing erythron compartment. Since the plasma compartment is usually very small ( 3 to 5 per cent) relative to the labile erythropoietic compartment, the fraction of the labile erythropoietic compartment fixed each day in maturing erythrons is approximately the same as the fraction of the combined plasma and labile erythropoietic compartments fixed each day in maturing erythrons; i.e.,

$$
\alpha_{23} \simeq \frac{X_{2}}{X_{1}+X_{2}} \alpha_{23}
$$

Whenever $X_{2}$ is not much greater than $X_{1}$, then the term $X_{2} /\left(X_{1}+X_{2}\right) \alpha_{23}$ should be substituted for $\alpha_{23}$ in the following equations. If labile radioiron for erythropoiesis (in plasma and labile erythropoietic pools) is designated as $L$, and radioiron irreversibly fixed in maturing erythrons is designated as $F$ and net incorporation of radioiron into circulating erythrocytes is designated as $N$, then,

$$
\begin{aligned}
d L / d t & =-\alpha_{23} L \\
d L / L & =-\alpha_{23} d t \\
\log L & =-\alpha_{23} t+C \\
L & =C^{\prime} e^{-\alpha_{23} t}, \text { since } L=N_{\max } \text { at } t=0, \\
L & =N_{\max } e^{-\alpha_{23} t}, \text { since } F+L=N_{\max }, \text { then } \\
F & =N_{\max }-N_{\max } e^{-\alpha_{23} t} \\
F & =N_{\max }\left(1-e^{-\alpha_{23} t}\right) .
\end{aligned}
$$

Using this relationship $F$ can be determined for all days of the study.

MEEHT $=t(N)-t(F)$ days.

Usually a nearly constant maximal time interval has been shown to exist between radioiron net incorporation into erythrons $(F)$ and net incorporation into erythrocytes $(N)$ only in the region of 10 to 30 per cent $N_{\max }$. As incorporation continues, the time interval narrows progressively (Figures 1,6). This is to be expected, since radioiron is fixed at all stages of erythron maturation and the half-time for transfer of iron from the erythropoietic labile pool to maturing erythrons is of the same order of magnitude as erythron maturation time: approximately 3 days from early proerythroblast (early rubroblast) to circulating reticulocyte (34). Under these circumstances, the best indication of MEEHT is to observe the time required for a small amount of radioiron fixed in erythrons in a relatively short time to emerge into the circulation. In normal individuals and in many pathologic conditions this time interval is maximal and nearly constant between the levels of 10 to 30 per cent $N_{\max }$. For this reason, 20 per cent $N_{\max }$ is chosen as a convenient level for measuring MEEHT. 
Since

$$
\begin{aligned}
F & =N_{\max }\left(1-e^{-\alpha_{23} t}\right) \\
N_{\max } / X & =N_{\max }\left(1-e^{-\alpha_{23} t_{1 / X}\left(F^{\prime}\right)}\right) \\
e^{-\alpha_{23} t_{1 / X}(F)} & =1-(1 / X) \\
t_{1 / X}(F) & =\frac{\log _{e}[X /(X-1)]}{\alpha_{23}} \\
t_{1 / 5}(F)=\frac{0.223}{\alpha_{23}} & t_{1 / 2}(F)=\frac{0.693}{\alpha_{23}}
\end{aligned}
$$

In some cases, however, when the erythropoietic labile pool is very small, as in iron deficiency, or when erythron fixation of iron is greatly increased, the intercompartmental rate constant $\alpha_{23}$ is greatly increased and most of the radioiron is transferred from the labile pool to maturing erythrons in a time which is very short compared with erythron maturation (Figure 13, sickle cell anemia, pernicious anemia) (22). Under these circumstances the time interval between $N$ and $F$ progressively increases as incorporation continues and the 50 per cent $N_{\max }$ level is chosen to measure MEEHT. Usually the time interval at $t_{1 / 5}(F)$ is used, but for values of $\alpha_{23}>0.4$, the time interval at $t_{1 / 2}(F)$ may be greater than at $t_{1 / 2}(F)$. In borderline cases MEEHT is calculated at both 20 and 50 per cent levels, the larger value being used:

$$
\begin{gathered}
\text { MEEHT }=t_{1 / 5}(N)-t_{1 / 5}(F) \\
\text { or whichever is larger } \\
t_{1 / 2}(N)-t_{1 / 2}(F)
\end{gathered}
$$

where $t_{1 / X}(N)$ and $t_{1 / X}(F)$ are the times for incorporation of $N_{\max } / X$ radioiron into erythrocytes and erythrons, respectively; and $N_{\max }=$ maximal net incorporation of radioiron into circulating erythrocytes; $t_{1 / 5}(N)$ and $t_{1 / 2}(N)$ are obtained directly from the erythrocyte radioiron net incorporation curve.

$$
\begin{aligned}
& t_{1 / 5}(F)=0.223 / \alpha_{23} \\
& t_{1 / 2}(F)=0.693 / \alpha_{23} .
\end{aligned}
$$

When $X_{2}$ is not $\gg X_{1}, X_{2} /\left(X_{1}+X_{2}\right) \alpha_{23}$ is used in the above equation in place of $\alpha_{23}$.

Examples

a) Endogenous hemochromatosis (Figure 13) (52-48).

$$
\alpha_{23}=0.173
$$

Since $\alpha_{23}$ is considerably less than 0.4

$$
\begin{aligned}
\operatorname{MEEHT} & =t_{1 / 5}(N)-t_{1 / 5}(F) \text { days } \\
t_{1 / 5}(F) & =0.223 / \alpha_{23}=1.3 \text { days }
\end{aligned}
$$

The net incorporation of radioiron into erythrocytes, Figure 13 (hemochromatosis), $N_{\max }=0.45$ and $N_{\max } / 5=0.09$ with corresponding $t_{1 / 5}(N)=3.0$ days.

$$
\text { MEEHT }=3.0-1.3=1.7 \text { days }
$$

To visualize the relationship of this time interval to the $F$ and $N$ curves, the $F$ curve may be quickly plotted using $t_{1 / 5}(F)$ and $t_{1 / 2}(F)=0.693 / 0.173=4.0$ days and calculating $t_{3 / 4}(F)$ and $t_{9 / 10}(F)$ as follows:

$$
\begin{aligned}
t_{3 / 4}(F)=\frac{\log _{e} X /(X-1)}{\alpha_{23}} & =\frac{\log _{e} 1.33 / 0.33}{\alpha_{23}} \\
= & \frac{\log _{e} 4}{\alpha_{23}}=\frac{1.39}{0.173}=8.0 \text { days }
\end{aligned}
$$

$$
\begin{aligned}
t_{9 / 10}(F)=\frac{\log _{e} 1.11 / 0.111}{\alpha_{23}} & =\frac{\log _{e} 10.0}{\alpha_{23}} \\
& =\frac{2.30}{0.173}=13.3 \text { days. }
\end{aligned}
$$

b) Sickle cell anemia (Figure 13).

$$
\alpha_{23}=4.74
$$

Since $\alpha_{23}$ is considerably greater than 0.4

$$
\begin{aligned}
\operatorname{MEEHT} & =t_{1 / 2}(N)-t_{1 / 2}(F) \\
t_{1 / 2}(F) & =0.693 / 4.74=0.15 \text { days. }
\end{aligned}
$$

The net incorporation of radioiron into erythrocytes, Figure 13 (sickle cell anemia), $N_{\max }=0.48$ and $N_{\max } / 2=0.24$ with corresponding $t_{1 / 2}(N)=1.45$ days.

$$
\text { MEEHT }=1.45-0.15=1.3 \text { days. }
$$

To plot $F$,

$$
\begin{aligned}
t_{1 / 5}(F) & =0.223 / 4.74=0.05 \text { days } \\
t_{1 / 2}(F) & =0.693 / 4.74=0.15 \text { days } \\
t_{3 / 4}(F) & =1.39 / 4.74=0.29 \text { days } \\
t_{9 / 10}(F) & =2.30 / 4.74=0.49 \text { days. }
\end{aligned}
$$

c) Pernicious anemia (Figure 13).

$$
\alpha_{23}=3.57
$$

Since $\alpha_{23}$ is considerably greater than 0.4

$$
\begin{aligned}
\text { MEEHT } & =t_{1 / 2}(N)-t_{1 / 2}(F) \\
t_{1 / 2}(F) & =0.693 / 3.57=0.19 \text { days. }
\end{aligned}
$$

The net incorporation of radioiron into erythrocytes, Figure 13 (pernicious anemia), $N_{\max }=0.14 ; N_{\max } / 2=0.07$ with corresponding $t_{1 / 2}(N)=5.2$ days.

$$
\text { MEEHT }=5.2-0.2=5.0 \text { days. }
$$

To plot $F$,

$$
\begin{aligned}
t_{1 / 5}(F) & =0.223 / 3.57=0.06 \\
t_{1 / 2}(F) & =0.693 / 3.57=0.19 \\
t_{3 / 4}(F) & =1.39 / 3.57=0.39 \\
t_{9 / 10}(F) & =2.30 / 3.57=0.65 .
\end{aligned}
$$


APPENDIX D

Calculations using iron kinetics models*

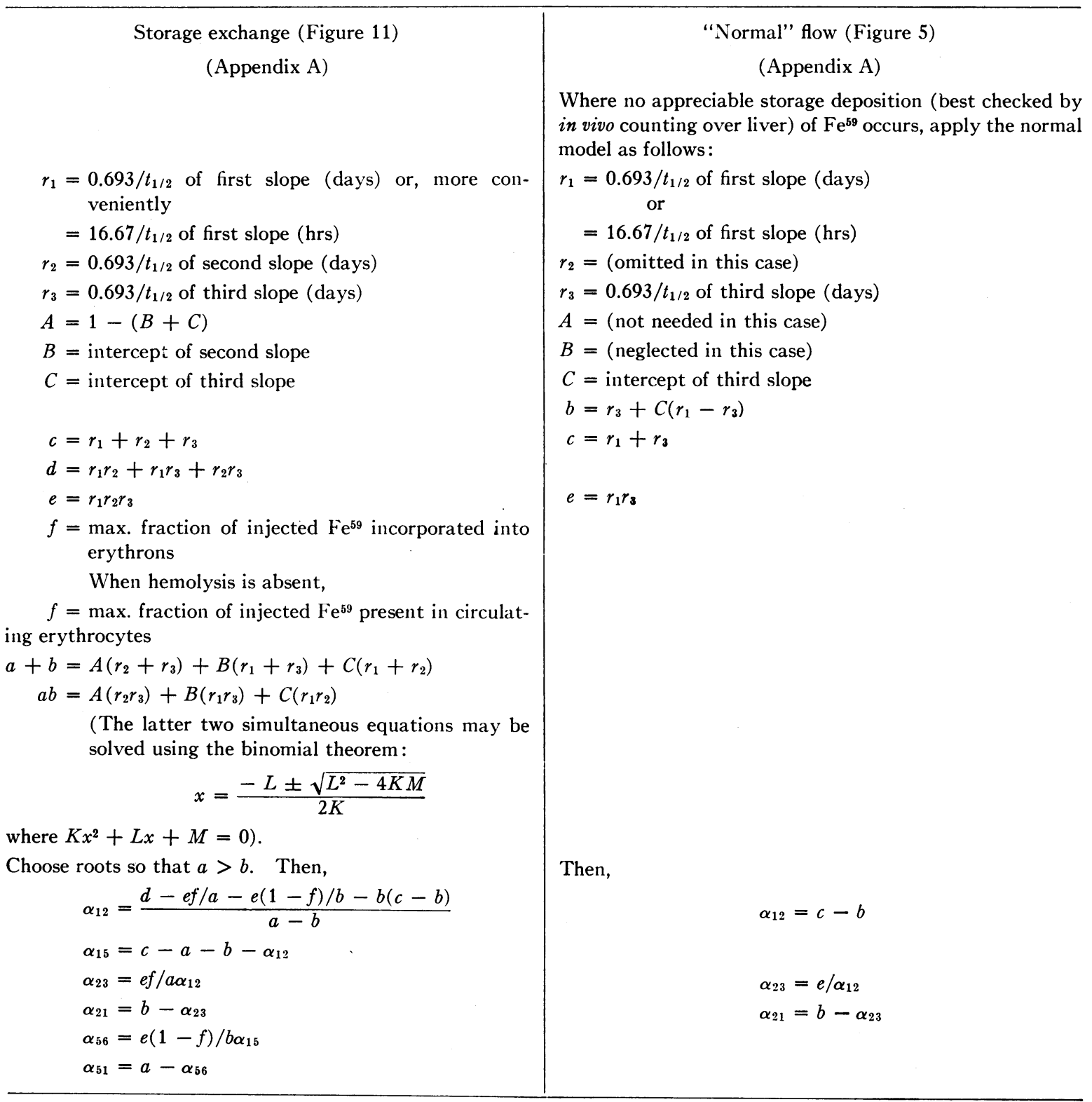

* Notation refers to kinetics models shown in Figures 5 and 11. 


\section{APPENDIX D-Continued}

Calculation of hemoglobin synthesis

(Appendix B)

Using $\alpha$ 's calculated from applicable model,

$X_{1}=$ amount of $\mathrm{Fe}$ in plasma compartment $(\mathrm{mg})$

$=$ plasma Fe $(\mu \mathrm{g} / \mathrm{ml}) \times$ plasma vol $(\mathrm{ml})$ $1,000(\mu \mathrm{g} / \mathrm{mg})$

$X_{2}=$ amount of $\mathrm{Fe}$ in labile erythropoietic pool $(\mathrm{mg})$

$$
=\alpha_{12} X_{1} / b
$$

Fe to hemoglobin

$$
\text { or } \quad(\mathrm{mg} / \text { day })=\alpha_{23} X_{2}
$$

RBC Fe turnover

Daily hemoglobin synthesis $(\mathrm{g})=\alpha_{23} X_{2} / 3.4$

Calculation of mean erythron life span

(Appendix B)

Mean erythron life span $=$ total-body hemoglobin (steady state condition) $=\frac{\text { daily hemoglobin synthesis }}{\text { dat }}$

Mean erythron life span (nonsteady state condition)

\section{total-body hemoglobin \\ $=\overline{\text { daily } \mathrm{Hb} \text { synthesis }+ \text { daily total } \mathrm{Hb} \text { decrement }}$}

or

- daily total $\mathrm{Hb}$ increment

Calculation of storage iron deposition

(Appendix B)

$X_{5}=$ amount of $\mathrm{Fe}$ in labile storage $(\mathrm{mg})$

$$
=\alpha_{15} X_{1} / a
$$

Fe to storage deposition $(\mathrm{mg} / \mathrm{day})=\alpha_{56} X_{5}$

Calculation of miscible storage iron

(Appendix B)

$$
X_{m s}=\left[(1-f) X_{1} / E\right] \mathrm{mg}
$$

Calculation of mean effective erythron hemoglobinization time

(Appendix C)

$$
\begin{aligned}
\text { MEEHT }= & t_{1 / 5}(N)-t_{1 / 5}(F) \\
& \text { or whichever is larger } \\
& t_{1 / 2}(N)-t_{1 / 2}(F)
\end{aligned}
$$

$t_{1 / 5}(N)$ and $t_{1 / 2}(N)$ are obtained from net incorporation of radioiron into circulating erythrocytes curve

$$
t_{1 / 5}(F)=0.223 / \alpha_{23} \quad t_{1 / 2}(F)=0.693 / \alpha_{23}
$$

When $X_{2}$ is not $\gg X_{1}, X_{2} /\left(X_{1}+X_{2}\right) \alpha_{23}$ is used in place of $\alpha_{23}$

\section{APPENDIX E}

Estimation of " $f$ " when both significant hemolysis and plasma-storage iron exchange are present.

Hepatic radioiron counting rates are used as a rough index of storage iron deposition. For patients with hemochromatosis without hemolysis, $f$ equals maximal net incorporation of radioiron into erythrocytes. Since hepatic radioactivity is expressed as $\mathrm{cpm} / \mathrm{cpm}_{\mathrm{o}}$ (hepatic ratio), the fraction of radioiron deposited in storage (chiefly in liver and bone marrow), $1-f$, results in an increase in hepatic ratio approximating $\left(\mathrm{cpm}_{\max } / \mathrm{cpm}_{\mathrm{o}}\right)-1$. Maximally, only a fraction $(f)$ of all radioiron is in circulating blood, so that a small error is involved in subtracting 1 instead of an amount slightly $<1$. If all radioiron were deposited in storage, then the calculated increase in hepatic ratio would be approximately $\frac{\left(\mathrm{cpm}_{\max } / \mathrm{cpm}_{\mathrm{o}}\right)-1}{1-f}$. Results obtained in the five patients without hemolysis are shown
TABLE III

Calculation of hepatic ratio increment for 100 per cent storage of radioiron in five patients with hemochromatosis and normal erythrocyte life span*

\begin{tabular}{cccc}
\hline \hline & $\begin{array}{c}\text { Maximum } \\
\text { hepatic } \\
\text { (cpm/ } \\
\text { cpmo)-1 }\end{array}$ & $1-f$ & $\begin{array}{c}\text { Hepatic ratio incre- } \\
\text { ment for 100\% } \\
\text { storage of radioiron } \\
\text { [max cpm/cpmo) } \\
-1] /(1-f)\end{array}$ \\
\hline Patient & & \\
\hline $53-57$ & 0.94 & 0.43 & 2.2 \\
$52-48$ & 1180 & 0.55 & 3.3 \\
$59-154$ & 0.75 & 0.25 & 3.0 \\
$60-9$ & 0.90 & 0.30 & 3.0 \\
$59-164$ & 0.96 & 0.56 & 1.7 \\
Mean of five patients & 2.6 \\
Mean of 14 patients with se- & \\
vere erythroid hypoplasia or \\
aplasia (21)
\end{tabular}

* Calculation and application are discussed in Appendix E. For comparison, results in ot her patients without significant hemolysis are also shown. 
in Table III. These measurements were made with a 1.75-inch diameter scintillation crystal recessed 1.4 inches in lead shielding, 2.5 inches thick, placed as shown in Appendix F. Mean hepatic ratio increase for 100 per cent storage of radioiron is 2.6 as compared with 2.6 in 14 other patients with severe erythroid hypoplasia or aplasia in which hemolysis was slight or absent. Marked hepatomegaly and obesity result in lower values; lean individuals without hepatomegaly have high values. A hepatic ratio increase for 100 per cent storage of radioiron of 3.0 was estimated for Patient 59-70, since he is lean, with only slight hepatomegaly. His measured maximal hepatic ratio is 1.78 (Figure 12). Since 100 per cent $\Delta$ hepatic ratio

$$
\begin{aligned}
& =\frac{\left(\mathrm{cpm}_{\max } / \mathrm{cpm}_{\mathrm{o}}\right)-1}{1-f}=3.0 \\
1-f & =\frac{1.78-1}{3.0}=0.26 \\
f & =0.74 .
\end{aligned}
$$

Measured net incorporation of radioiron into circulating erythrocytes at $\mathbf{1 0}$ days is $\mathbf{0 . 6 3}$. The relatively moderate decrease of net incorporation of radioiron into erythrocytes, from the calculated value of $f$ of 0.74 to the observed net incorporation of $\mathbf{0 . 6 3}$, is consistent with the moderately shortened calculated mean erythron life span of 52 days as judged by 1) theoretical estimation that a 10 per cent de- crease of maximal net erythrocyte incorporation corresponds to daily breakdown of 1.5 to 3.5 per cent of newly formed erythrocytes, and 2) observations in many patients with varying degrees of hemolysis and negligible storage iron deposition (21)

Similar analyses, using splenic ratios derived in patients with erythropoiesis occurring chiefly in spleen or in patients with intense splenic sequestration of erythrocytes, are helpful as a check for estimating $f$ in cases involving both considerable plasma-storage iron exchange and splenic sequestration of erythrocytes. In comparing hepatic and splenic counting rates with sacral counting rates obtained with broad collimation of a 1.75 - to 2 -inch crystal, it must be kept in mind that the sacral area and adjoining ileum are estimated to represent roughly one-eighth of active marrow, while liver represents roughly one-half of iron storage (35) and is at an average greater distance from the crystal. A factor of approximately one-half should be used for multiplication of hepatic ratio increments as an index of storage for comparison with sacral ratio increments (when red marrow volume is not significantly increased) as an index of erythropoiesis. Similar considerations for spleen lead to the use of factors ranging from one-half to onequarter for comparison of splenic erythropoiesis or splenic sequestration with marrow erythropoiesis (21); enlargement of spleen results in decreased splenic counting rate splenic radioiron remaining constant.

\section{APPENDIX F}

Placement of scintillation counters for surface measurement ${ }^{1}$

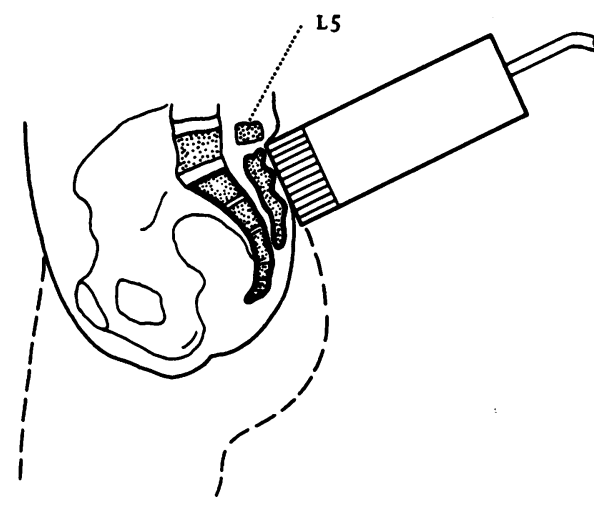

Sagittal section through pelvis showing sacrum and position of scintillation detector.

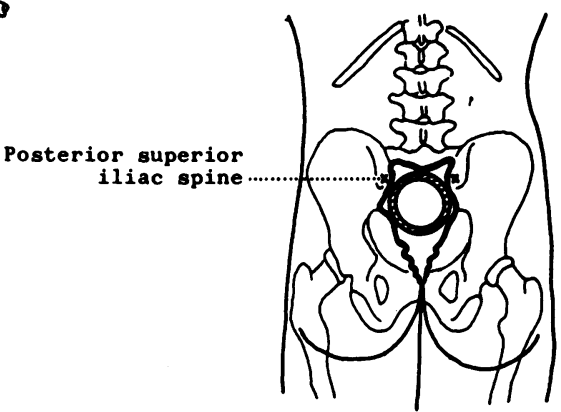

Posterior surface projection of sacrum showing position of scintillation detector.

Fig. 21. External counting of sacrum.

\footnotetext{
${ }^{1}$ For positions of detector head for external counting of spleen, liver, and sacrum, see Figures 21 and 22.
} 

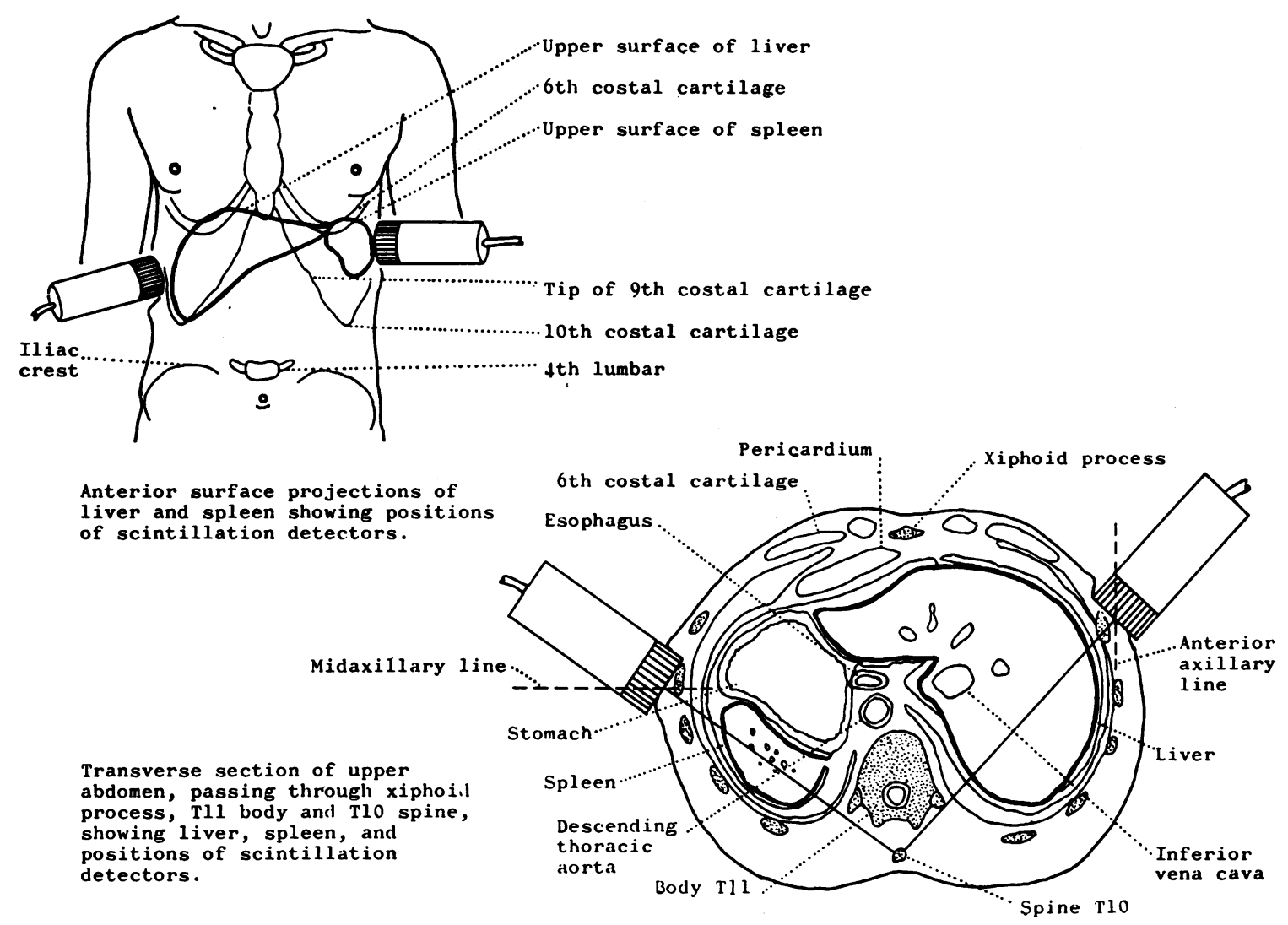

Fig. 22. External counting of liver and spleen.

Surface landmarks: Usual vertebral levels in quiet respiration

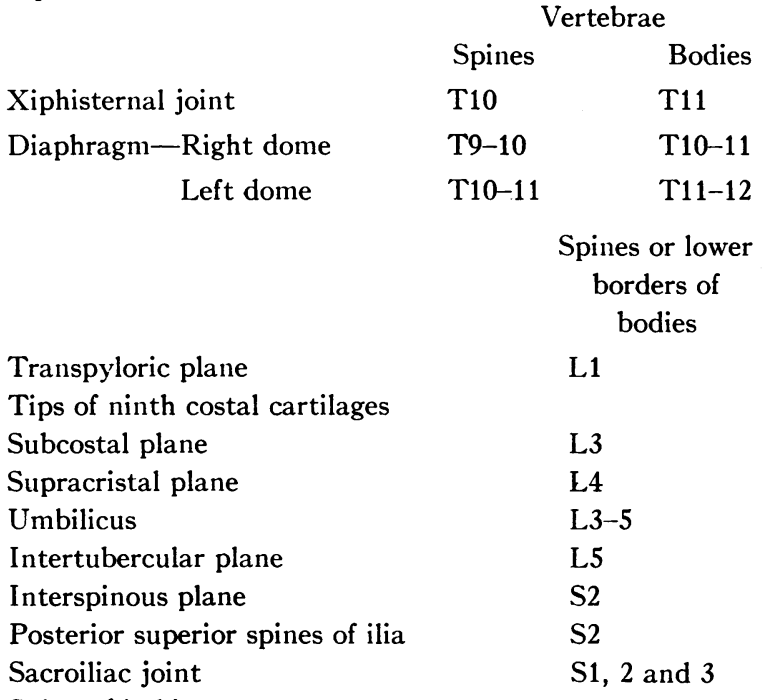

Spine of ischium

Center of acetabulum

Upper margin of symphysis pubis

\section{REFERENCES}

1. Huff, R. L., Hennessy, T. G., Austin, R. E., Garcia, J. F., Roberts, B. M., and Lawrence, J. H. Plasma and red cell iron turnover in normal subjects and in patients having various hematopoietic disorders. J. clin. Invest. 1950, 29, 1041.

2. Huff, R. L., Elmlinger, P. J., Garcia, J. F., Oda, J. M., Cockrell, M. C., and Lawrence, J. H. Ferrokinetics in normal persons and in patients having various erythropoietic disorders. J. clin. Invest. 1951, 30, 1512.

3. Elmlinger, P. J., Huff, R. L., Tobias, C. A., and Lawrence, J. H. Iron turnover abnormalities in patients having anemia: Serial blood and in vivo tissue studies with $\mathrm{Fe}^{60}$. Acta haemat. (Basel) 1953, 9, 73.

4. Huff, R. L., and Judd, O. J. Kinetics of iron metabolism in Advances in Biological and Medical Physics, J. H. Lawrence and C. A. Tobias, Eds. New York, Academic Press, 1956, vol. 4, p. 223.

5. Pollycove, M., and Mortimer, R. The quantitative determination of individual iron kinetics and hemoglobin formation in human subjects. Clin. Res. Proc. 1956, 4, 51. 
6. Pollycove, M., and Mortimer, R. The quantitative determination of individual hemoglobin formation and iron kinetics in human subjects in Proc. 6th Int. Congress of the Int. Soc. of Hematol. New York, Grune \& Stratton, 1958, p. 313.

7. Pollycove, M. Iron metabolism in Thannhausers Lehrbuch des Stoff wechsels und der Stoffwechselkrankheiten, 2nd ed., N. Zollner, Ed. Stuttgart, Georg Thieme, 1957, p. 835. (English edition, Grune \& Stratton, in press.)

8. Pollycove, M. Iron kinetics in Iron in Clinical Medicine, R. O. Wallerstein, Ed. Berkeley, Univ. of Calif. Press, 1958, p. 43.

9. Bothwell, T. H., Callender, S., Mallett, B., and Witts, L. J. The study of erythropoiesis using tracer quantities of radioactive iron. Brit. J. Haemat. 1956, $2,1$.

10. Bothwell, T. H., Hurtado, A. V., Donohue, D. M., and Finch, C. A. Erythrokinetics. IV. The plasma iron turnover as a measure of erythropoiesis. Blood 1957, 12, 409.

11. Finch, C. A., Bothwell, T. H., and Donohue, D. M. Ferrokinetics in Proc. 6th Int. Congress of the Int. Soc. of Hematol. New York, Grune \& Stratton, 1958 , p. 259.

12. Giblett, E. R., Coleman, D. H., Pirzio-Biroli, G., Donahue, D. M., Motulsky, A. G., and Finch, C. A. Erythrokinetics. Quantitative measurements of red cell production and destruction in normal subjects and patients with anemia. Blood 1956, 11, 291.

13. Bush, J. A., Ashenbrucker, H., Cartwright, G. E., and Wintrobe, M. M. The anemia of infection. $X X$. The kinetics of iron metabolism in the anemia associated with chronic infection. J. clin. Invest. 1956, 35, 89.

14. Keiderling, W., Schmidt, H. A. E., and Lee, M. Untersuchungen ïber die Dynamik des Erythrozytenumsatzes mit Radioeisen $\left(\mathrm{Fe}^{59}\right)$ und Radiochrom $\left(\mathrm{Cr}^{51}\right)$ in Radioaktive Isotope in Klinik und Forschung, Band II, K. Fellinger and H. Vetter, Eds. München, Urban \& Schwarzenberg, 1956.

15. Sharney, L., Schwartz, L., Wasserman, L. R., Port, S., and Leavitt, D. Pool systems in iron metabolism; with special reference to polycythemia vera. Proc. Soc. exp. Biol. (N. Y.) 1954, 87, 489.

16. Sharney, L., Wassermann, L. R., Schwartz, L., Tendler, D., and Vroman, L. Extension of analysis of iron kinetics in terms of multiple pool systems. Proc. 6th Int. Congress of the Int. Soc. of Hematol. New York, Grune \& Stratton, 1958, p. 314.

17. Ashby, W. Determination of the length of life of transfused blood corpuscles in man. J. exp. Med. 1919, 29, 267.

18. Ashby, W. The span of life of the red blood cell: A résumé. Blood 1948, 3, 496.

19. Eadie, G. S., and Brown, I. W., Jr. Red blood cell survival studies. Blood 1953, 8, 1110.
20. Pollycove, M., Elmlinger, P. J., Sarkes, L. A., Apt, L., and Ross, J. F. Radioiron determination of human erythrocyte life-span distribution. Clin. Res. Proc. 1956, 4, 79.

21. Pollycove, M. Unpublished observations.

22. Pollycove, M. Ferrokinetics: Techniques in Eisenstoff wechsel, W. Keiderling, Ed. Stuttgart, Georg Thieme 1959, p. 20.

23. Finch, S. C., and Finch, C. A. Idiopathic hemochromatosis, an iron storage disease; iron metabolism in hemochromatosis. Medicine (Baltimore) 1955, 34, 381.

24. Wetzel, R. A., Murray, W. E., and Pollycove, M. Iron absorption and kinetics in a pre-hemochromatotic patient with familial endogenous hemochromatosis. To be published.

25. Loeffler, R. K., Rappoport, D. A., and Collins, V. P. Radioiron citrate as tracer to determine disappearance rate of plasma iron in normal subjects. Proc. Soc. exp. Biol. (N. Y.) 1955, 88, 441.

26. Anger, H. O. Scintillation counters for the measurement of radioactive samples. University of California Lawrence Radiation Laboratory Report no. 886, August 30, 1950.

27. Peters, T., Giovanniello, T. J., Apt, L., and Ross, J. F. I. A new method for the determination of serum iron binding capacity; II. A simple improved method for the determination of serum iron. J. Lab. clin. Med. 1956, 48, 274, 280.

29. Apt, L., Pollycove, M., and Ross, J. F. Idiopathic pulmonary hemosiderosis. A study of the anemia and iron distribution using radioiron and radiochromium. J. clin. Invest. 1957, 36, 1150.

29. Berlin, N. I., Lawrence, J. H., and Gartland, J. Blood volume in polycythemia as determined by $\mathrm{P}^{32}$ labeled red blood cells. Amer. J. Med. 1950, 9, 747.

30. Hallgren, B. Haemoglobin formation and storage iron in protein deficiency. Acta Soc. Med. upsalien. 1954, 59, 79.

31. Høyer, R. Physiologic variations in the iron content of human blood serum. I. The variations from week to week, from day to day and through twenty-four hours. Acta med. scand. 1944, 119, 562.

32. Laurell, C. B. Diurnal variation of serum iron concentration. Scand. J. clin. Lab. Invest. 1953, 5, 118.

33. Pollycove, M., and Lawrence, J. H. Erythrocyte kinetics in patients with polycythemia vera. Clin. Res. 1958, 6, 191.

34. Pollycove, M. Erythrocyte kinetics in refractory anemia with erythroid hyperplasia in Proc. 7th Congress of Int. Soc. of Hematol. New York, Grune \& Stratton, 1960, vol. I, p. 465.

35. Shoden, A., Gabrio, B. W., and Finch, C. A. The relationship between ferritin and hemosiderin in rabbits and man. J. biol. Chem. 1953, 204, 823. 
36. Heilmeyer, L. Ferritin in Iron in Clinical Medicine, R. O. Wallerstein, Ed. Berkeley, Univ. of Calif. Press, 1958, p. 24.

37. Lajtha, L. G., and Suit, H. D. Cptake of radioactive iron $\left({ }^{50} \mathrm{Fe}\right)$ by nucleated red cells in vitro. Brit. J. Haemat. 1955, 1, 55.

38. Suit, H. D., Lajtha, L. G., Oliver, R., and Ellis, F. Studies on the ${ }^{59} \mathrm{Fe}$ uptake by normoblasts and the failure of X-irradiation to affect uptake. Brit. J. Haemat. 1957, 3, 165.

39. Osgood, E. E. Number and distribution of human hemic cells. Blood 1954, 9, 1141.

40. Patt, H. M. A consideration of myeloid-erythroid balance in man. Blood 1957, 12, 777.

41. Bessis, M., and Breton-Gorius, J. Etude au microscope électronique des granulations ferrugineuses des érythrocytes normaux et pathologiques. Anémies hémolytiques. Hémoglobinopathies. Saturnisme. Rev. Hémat. 1957, 12, 43.

42. Bessis, M., and Breton-Gorius, J. Etude au microscope électronique du sang et des organes hematopoietiques dans le saturnisme experimental. (Cycle du fer figure.) Sem. Hôp. Paris 1957, 33, 411.

43. Bessis, M. Erythropoiesis as seen with the electron microscope in Kinetics of Cellular Proliferation, F. Stohlman, Jr., Ed. New York, Grune \& Stratton, 1959, p. 22.

44. Granick, S. Ferritin; its properties and significance for iron metabolism. Chem. Rev. 1946, 38, 379.

45. Granick, S. Ferritin: Increase of protein apoferritin in gastrointestinal mucosa as direct response to iron feeding; function of ferritin in regulation of iron absorption. J. biol. Chem. 1946, 164, 737.

46. Granick, S. Structure and physiological functions of ferritin. Physiol. Rev. 1951, 31, 489.

47. Granick, S. Iron metabolism. Bull. N. Y. Acad. Med. 1954, 30, 81.

48. Heilmeyer, L., Wöhler, F., and Keiderling, W. Eine neue Methode zur quantitativen Bestimmung von Ferritin in den Organen und ihre vorläufigen Ergebnisse. Acta haemat. (Basel) 1954, 12, 154.

49. Heilmeyer, L., and Weissbecker, L. Funktion und Stoff wechsel der Schwermetalle in Handbuch der Allgemeinen Pathologie, F. Büchner, E. Letterer and F. Roulet, Eds. Berlin, Springer-Verlag, 1957, vol. 4 , part 2 , p. 1 .

50. Hampton, J. K., Jr., and Mayerson, H. S. Hemoglobin iron as stimulus for production of ferritin by the kidney. Amer. J. Physiol. 1950, 160, 1.

51. Tecce, Di G., and Tecce, R. Presenza di ferritina nella placenta umana a termine di gravidanza. Quad. Nutr. 1950, 11, 42.

52. Laurell, C. B. Studies on the transportation and metabolism of iron in the body. Acta physiol. scand. 1947, 14, suppl. 46.

53. Laurell, C. B. Iron transportation in Iron in Clinical Medicine, R. O. Wallerstein, Ed. Berkeley, Univ. of Calif. Press, 1958, p. 8.
54. Sondhaus, C. A., and Thorell, B. Microspectrophotometric determination of nonheme iron in maturing erythroblasts and its relationship to the endocellular hemoglobin formation. Blood 1960, 16, 1285.

55. Walsh, R. J., Thomas, E. D., Chow, S. K., Fluharty, R. G., and Finch, C. A. Iron metabolism: Heme synthesis in vitro by immature erythrocytes. Science 1949, 110, 396.

56. Jandl, J. H., Inman, J. K., Simmons, R. L., and Allen, D. W. Transfer of iron from serum iron-binding protein to human reticulocytes. J. clin. Invest. 1959, 38, 161.

57. Dubach, R., Moore, C. V., and Callender, S. Studies in iron transportation and metabolism. IX. The excretion of iron as measured by the isotope technique. J. Lab. clin. Med. 1955, 45, 599.

58. Johnston, F. A., Frenchman, R., and Boroughs, E. D. Absorption of iron from beef by women. J. Nutr. 1948, 35, 453.

59. McMillan, T. J., and Johnston, F. A. Absorption of iron from spinach by six young women, and effect of beef upon the absorption. J. Nutr. 1951, 44, 383.

60. Moore, C. V. Importance of nutritional factors in pathogenesis of iron-deficiency anemia. Amer. J. clin. Nutr. 1955, 3, 3.

61. Moore, C. V., and Dubach, R. Metabolism and requirements of iron in the human: Report to Council on Foods and Nutrition. J. Amer. med. Ass. 1956, 162, 197.

62. Steinkamp, R., Dubach, R., and Moore, C. V. Studies in iron transportation and metabolism. VIII. Absorption of radioiron from iron-enriched bread. A. M. A. Arch. intern. Med. 1955, 95, 181.

63. Schulz, J., and Smith, N. J. A quantitative study of the absorption of food iron in infants and children. A.M.A. Amer. J. Dis. Child. 1958, 95, 109.

64. Walsh, R. J., Kalder, I., Brading, I., and George, G. P. The availability of iron in meat: Some experiments with radioactive iron. Aust. Ann. Med. 1955, 4, 272.

65. Josephs, H. W. Iron metabolism and the hypochromic anemia of infancy. Medicine (Baltimore) 1953, 32, 125.

66. Josephs, H. W. Absorption of iron as a problem in human physiology; a critical review. Blood 1958, $13,1$.

67. Callender, S. T. Iron absorption. Brit. med. Bull. $1959,15,5$.

68. London, I. M., West, R., Shemin, D., and Rittenberg, D. On the origin of bile pigment in normal man. J. biol. Chem. 1950, 184, 351.

69. Gray, C. H., Neuberger, A., and Sneath, P. H. A. Studies in congenital porphyria. 2. Incorporation of ${ }^{15} \mathrm{~N}$ in the stercobilin in the normal and in the porphyric. Biochem. J. 1950, 47, 87.

70. Peabody, F. W., and Broun, G. O. Phagocytosis of erythrocytes in the bone marrow, with special 
reference to pernicious anemia. Amer. J. Path. 1925, 1, 169.

71. Block, M. The morphology of erythropoiesis in Mechanism of Anemia, I. M. Weinstein, Ed. To be published.

72. Feichtmeier, T., and Pollycove, M. Unpublished observations.

73. Wallerstein, R. O., and Pollycove, M. Bone marrow hemosiderin and ferrokinetics patterns in anemia. A. M. A. Arch. intern. Med. 1958, 101, 418.

74. Pollycove, M. Bone marrow hemolysis in anemia (abstract). J. clin. Invest. 1959, 38, 1031.

75. Gitlin, D., Janeway, C. A., and Farr, L. E. Studies on the metabolism of plasma proteins in the nephrotic syndrome. I. Albumin, $\gamma$-globlin and iron-binding globulin. J. clin. Invest. 1956, 35, 44.

76. Gitlin, D. Distribution dynamics of circulating and extravascular $\mathrm{I}^{131}$ plasma proteins. Ann. N. Y. Acad. Sci. 1957, 70, 122.

77. Dobson, E. Personal communication.

78. Spellberg, M. A. Diseases of the Liver. New York, Grune \& Stratton, 1954.
79. Stohlman, F., Jr. Observations on the kinetics of red cell proliferation in The Kinetics of Cellular Proliferation, F. Stohlman, Jr., Ed. New York, Grune \& Stratton, 1959, p. 318.

80. Osgood, E. E. Regulation of cell proliferation in The Kinetics of Cellular Proliferation, F. Stohlman, Jr., Ed. New York, Grune \& Stratton, 1959, p. 282.

81. Alpen, E. L., and Cranmore, D. Observations of the regulation of erythropoiesis and on cellular dynamics by $\mathrm{Fe}^{59}$ autoradiography in The Kinetics of Cellular Proliferation, F. Stohlman, Jr., Ed. New York, Grune \& Stratton, 1959, p. 290.

82. Erslev, A. J. Control of the proliferative steady state in The Kinetics of Cellular Proliferation, F. Stohlman, Jr., Ed. New York, Grune \& Stratton, 1959, p. 312.

83. London, I. M., and West, R. The formation of bile pigment in pernicious anemia. J. biol. Chem. 1950, 184, 359.

84. Pollycove, M., Apt, L., and Ross, J. F. Erythropoiesis and the movement of iron in patients with pernicious anemia. Clin. Res. Proc. 1955, 3, 92.

\section{CORRECTION}

On page 27 of the paper entitled "Quantitative studies of nasal carriers of staphylococci among hospitalized patients" by Arthur White ( $\mathrm{J}$. clin. Invest. 1961, 40, 23), the parenthetical expression in the footnote to Table VI should read $\left(x^{2}: \mathrm{p}<0.01\right)$. The $\mathrm{p}$ value was given incorrectly as $<0.1$.

On page 491 of the article entitled "Effects of infusions of serum albumin on serum lipids and lipoproteins in nephrosis" by James $\mathrm{H}$. Baxter, Howard C. Goodman and James C. Allen (J. clin. Invest. 1961, 40, 490), the subheading under "Plasma volume" in Table I should be "I/II" instead of "II/I." 